\title{
Atividades farmacológicas e sua relação com o estresse oxidativo de Morinda citrifolia
}

\section{L. (Rubiaceae): uma revisão integrativa}

\author{
Pharmacological activities and their relationship with the oxidative stress of Morinda Citrifolia $\mathrm{L}$.
}

(Rubiaceae): an integrative review

Actividades farmacológicas y su relación com el estrés oxidativo de Morinda Citrifolia L.

(Rubiaceae): una revisión integradora

Recebido: 22/03/2021 | Revisado: 30/03/2021 | Aceito: 01/04/2021 | Publicado: 11/04/2021

Nathália Cássia Gomes de Sousa

ORCID: https://orcid.org/0000-0002-9524-0183 Universidade Federal do Pará, Brasil E-mail: cassiagomes2007@gmail.com

Lucas dos Santos Nunes

ORCID: https://orcid.org/0000-0003-3063-9617 Universidade Federal do Pará, Brasil E-mail: lucasfarmaufpa@gmail.com

Hanna Patrícia dos Santos Martins

ORCID: https://orcid.org/0000-0002-3486-4048 Universidade Federal do Pará, Brasil E-mail: hannamartins77@gmail.com

Sandro Percário

ORCID: https://orcid.org/0000-0002-9528-0361 Universidade Federal do Pará, Brasil

E-mail: percario@ufpa.br

Maria Fâni Dolabela

ORCID: https://orcid.org/0000-0003-0804-5804 Universidade Federal do Pará, Brasil E-mail: fanidolabela20@gmail.com

\begin{abstract}
Resumo
O presente trabalho fez uma análise de estudos farmacológicos de Morinda citrifolia L. e o papel do estresse oxidativo. A pesquisa foi realizada no Portal de Periódicos da Capes e PubMed. Inicialmente, foram lidos os títulos, resumos e excluídos os que não tinham relação com o tema e em duplicidade. Após esse processo, os trabalhos foram lidos na íntegra e realizada a extração das informações. Foram encontrados no total 517 artigos, após a leitura dos títulos e resumos, foram selecionados 39 artigos e ao final incluídos 28 . Em relação às atividades avaliadas, 9 artigos avaliaram a atividade antioxidante e anti-inflamatória; 5 antitumoral e citotoxicidade; 3 antimicrobianos; 3 antileishmania; e 8 artigos que pesquisaram sobre diferentes atividades. De acordo com os estudos analisados esta espécie possui potencial anti-inflamatório, hipotensor, prevenção de pancreatite, hepatoprotetor e citoprotetor, e tais atividades parecem estar relacionadas a presença de metabólitos com atividade antioxidantes. A atividade antitumoral pode estar relacionada à atividade oxidante das antraquinonas. A participação do estresse oxidativo no efeito hipoglicemiante e antiobesidade da espécie ainda precisa ser melhor investigada. Em síntese, a maioria das atividades biológicas atribuídas a $M$. citrifolia pode ser relacionada a presença de compostos com potencial antioxidante.

Palavras-chave: Morinda citrifolia; Estresse oxidativo; Flavonoide; Iridoide; Antraquinona.
\end{abstract}

\begin{abstract}
The present work made an analysis of pharmacological studies of Morinda citrifolia L. and the role of oxidative stress. The research was carried out on the Capes and PubMed Journals Portal. Initially, titles, abstracts were read and those that had no relation to the topic and in duplicate were excluded. After this process, the works were read in full and the information was extracted. A total of 517 articles were found, after reading the titles and abstracts, 39 articles were selected and at the end 28 were included. Regarding the activities evaluated, 9 articles evaluated the antioxidant and anti-inflammatory activity; 5 antitumor and cytotoxicity; 3 antimicrobials; 3 antileishmania; and 8 articles that researched about different activities. According to the studies analyzed, this species has anti-inflammatory, hypotensive potential, prevention of pancreatitis, hepatoprotective and cytoprotective, and such activities seem to be related to the presence of metabolites with antioxidant activity. The antitumor activity may be related to the oxidizing activity of anthraquinones. The role of oxidative stress in the hypoglycemic and anti-obesity effects of the species still
\end{abstract}


needs to be further investigated. In summary, most of the biological activities attributed to $M$. citrifolia can be related to the presence of compounds with antioxidant potential.

Keywords: Morinda citrifolia; Oxidative stress; Flavonoid; Iridoide; Anthraquinone.

\section{Resumen}

El presente trabajo realizó un análisis de los estudios farmacológicos de Morinda citrifolia L. y el papel del estrés oxidativo. La investigación se realizó en el Portal de Revistas Capes y PubMed. Inicialmente se leyeron títulos, resúmenes y se excluyeron aquellos que no tuvieran relación con el tema y por duplicado. Luego de este proceso, se leyeron las obras íntegramente y se extrajo la información. Se encontraron un total de 517 artículos, luego de la lectura de títulos y resúmenes se seleccionaron 39 artículos y al final se incluyeron 28. En cuanto a las actividades evaluadas, 9 artículos evaluaron la actividad antioxidante y antiinflamatoria; 5 antitumoral y citotoxicidad; 3 antimicrobianos; 3 antileishmania; y 8 artículos que investigaron sobre diferentes actividades. Según los estudios analizados, esta especie tiene potencial antiinflamatorio, hipotensor, preventivo de pancreatitis, hepatoprotector y citoprotector, y dichas actividades parecen estar relacionadas con la presencia de metabolitos con actividad antioxidante. La actividad antitumoral puede estar relacionada con la actividad oxidante de las antraquinonas. El papel del estrés oxidativo en los efectos hipoglucémicos y antiobesidad de la especie aún necesita ser investigado más a fondo. En resumen, la mayoría de las actividades biológicas atribuidas a M. citrifolia pueden estar relacionadas con la presencia de compuestos con potencial antioxidante.

Palabras clave: Morinda citrifolia; Estrés oxidativo; Flavonoide; Iridoide; Antraquinona.

\section{Introdução}

As plantas medicinais, presentes na cultura popular de diversos povos, são vastamente desenvolvidas através do empirismo e da observação que são passadas entre gerações, sobretudo entre a população que tem dificuldade em acessar os serviços de saúde (Vásquez, Mendonça \& Noda, 2014). Em reunião da Organização Mundial da Saúde (1978), foi recomendado que os Estados signatários desenvolvessem políticas de inclusão das plantas medicinais e fitoterápicos nos serviços de saúde, entretanto, somente em 2006, o Brasil publicou a Política Nacional de Plantas Medicinais e Fitoterápicos (Brasil, 2006). Diferentes espécies vegetais foram incluídas na Relação Nacional de Plantas Medicinais de Interesse ao Sistema Único de Saúde (SUS) (2015), no entanto, outras espécies exóticas utilizadas na medicina popular não foram incluídas nesta relação, um exemplo é a Morinda citrifolia L. (Rubiaceae) conhecida popularmente como noni.

Essa espécie é originária do sudoeste da Ásia e teve boa adaptação em territórios tropicais, como o Brasil (Barbosa, et al., 2017). Sua utilização medicinal e como alimento tem sido reportada por grupos indígenas da Oceania há mais de 2.000 anos, sendo relatada sua atividade na promoção de homeostase do organismo (Wang \& Su, 2001). Na Polinésia, ela é usada para o tratamento de diabetes, câncer, hipertensão, desordens menstruais, artrite, como antimicrobiano, anti-inflamatório e antioxidante (Potterat \& Hamburger, 2007; West, et al., 2007; Rao \& Subramanian, 2009).

$\mathrm{O}$ estresse oxidativo pode promover danos às macromoléculas e à membrana celular. Podendo causar disfunção endotelial, inflamação, alteração na função mitocondrial e padrão de metilação do DNA (Gottlieb, et al., 2011). Uma série de doenças podem ter relação ao estresse oxidativo e como exemplos, pode-se citar: câncer, aterosclerose, diabetes, artrite, malária, AIDS, doenças do coração. Plantas que contém substâncias, como compostos fenólicos, com capacidade antioxidante podem retardar ou inibir a oxidação de lipídios ou outras moléculas. Essas desempenham um importante papel na absorção e neutralização de radicais livres, quelando o oxigênio e prevenindo o dano dos radicais livres ao organismo, sendo promissores em termos terapêuticos (Degáspari \& Waszczynskyj, 2004).

Muitos estudos químicos já foram realizados com a espécie levando a identificação de diferentes classes de metábolitos e inúmeros compostos, tais como: Flavonoides - rutina, quercetina, isoquercetina e kaempferol rutnosídeo; Compostos fenólicos - ácido vanílico e vanilina; Iridoides - menotropina, ácido diacetil-asperulosidico, ácido asperulósido, ácido desacetil-asperulósido, ácido geniposídico, ácido isoasperulosídico, acetato harpagide, ácido asperulosídico, rehmannioside A, asperolosído, morindacina, asperuloside e citrifolinina; Cumarinas - escopoletina e esculetina; Antraquinonas - 3-O-primeverose-1,6,8-trihydroxy-2-metil-antraquinona, 1-Ó-primeverose-3-metoxi-8-hidroxi-2-metilol- 
antraquinona; 1-Ó-gentiobiose-2-metilol-antraquinona, 1-O- $\beta$-d-glycopyranosyl-8-metoxi-emodin, 1-Ó-primeverose-3,8dimethoxy-2-metil-antraquinona, 1-O-gentiobiose-emodin, 1-O-primeverose-aloeemodin, 3-O-gentiobiose -1-hidroxi-2-metilantraquinona, 8-0-primeverose-1-metoxi-3-hidroxi-2-metil-antraquinona, 3-Ó-primeverose-8metoxi-1-hidroxi-2-metil-antraquinona, 8-O-primeverose-1,3-dihidroxy-2-metil-antraquinona, 1-O-gentiobiose -3-hidroxi-2metil-antraquinona, emodin 1-O- $\beta$-d-glycopyranosyl, 1-Ó-primeverose-3,8-dihidroxy-2-metil-antraquinona, 1-Ó-gentiobiose8-metoxi-aloeemodin, 1-Ó-primeverose-8-metoxi-3-hidroxi-2-metil-anthraquinona, 1-O-primeverose-3,4-dimethoxy-2hidroxi-anthraquinona, 3-O-primeverose-1,8-dihidroxi-2-metil -antraquinona, 1-Ó-primeverose-2- metilol-3-hidroxi-8-metoxianthraquinona, 1-O- $\beta$-d-glicopiranosilrubiadin3-metil éter, 1-O-primeverose-2-metilol-anthraquinona, 1-O- $\beta$-d-glicopiranosilemodin, 1-O-gentiobiose-emodin, 1-O-primeverose-8-hidroxi-ibericin, 8-O-gentiobiose-emodin, 1-O-primeverose-rubiadin, 1O-primeverose-emodin, 1-O-primeverose-2-metil-3,6,8-trihidroxi-antraquinona, 1-hidroxi-2-metilol-anthraquinona, aloeemodin, 1-metil-3-hidroxi-anthraquinona, rubiadin, fridamicina E, emodin, 3-hidroxi-2-metilol-antraquinona, 1-hidroxi-2metil-antraquinona, 1,3-dihidroxi-2-metoxi-antraquinona, rubiadin 3-metil éter, rubiadin 1-metil éter, ibericin; Terpenoides -

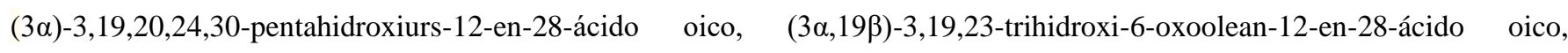

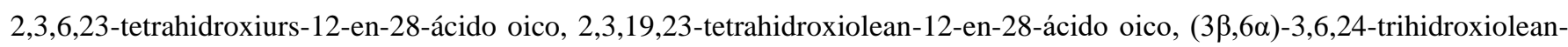

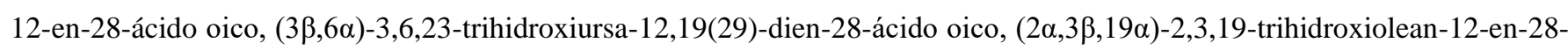

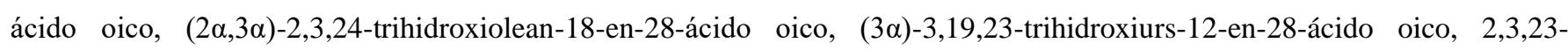
trihidroxiurs-12-en-28-ácido oico, butil $(3 \beta, 7 \beta, 12 \beta)$-12-acetoxia-3,7-dihidroxy-4,4,14-trimetil-11,15-dioxochol-8-en-24-oate, (1 $\alpha, 3 \beta, 9 \beta)$-24-hidroperoxi-1,3-dihydroxi-5-metil-9,19-ciclolanost-25-en-28-ácido oico, hederagenina, ácido maslínico, camphoratina H (Almeida-Sousa, et al., 2016a, Almeida-Sousa, et al., 2016b, Dussossoy, et al., 2016; Wigati, et al., 2016; Almeida-Sousa, et al., 2018; Chen, et al., 2018; Gadicherla, et al., 2019, Narasimhan, et al., 2019; Yang, et al., 2019; Trieu Ly, et al., 2020; Wang, et al., 2020).

Essa espécie tem sido foco de vários estudos de avaliação de sua atividade, o presente trabalho fez uma análise de estudos farmacológicos de M. citrifolia, possível responsável pelas inúmeras atividades alegadas, em que se destaca, a participação do estresse oxidativo nestas.

\section{Metodologia}

Este trabalho utilizou o método comparativo, do tipo quali-quantitativo, em que os estudos foram compilados e, posteriormente, avaliados os potenciais das atividades farmacológicas de $M$. citrifolia comparando com os controles positivos e negativos em testes in vitro e in vivo (Pereira, et al., 2018; Brandão, et al., 2020).

Foi realizado inicialmente, o levantamento bibliográfico dos últimos 5 anos, sobre o efeito farmacológico da espécie M. citrifolia no Portal de Periódicos CAPES/MEC. Para essa busca foram utilizadas as strings: "Pharmacological potential of Morinda citrifolia species OR Pharmacological activity of the species Morinda citrifolia" onde foram encontrados 206 artigos revisados por pares, e "Morinda citrifolia AND anticancer activity" estando disponível 219 artigos também revisados por pares (Figura 1).

Para a condução da pesquisa foram recuperados na máquina de busca artigos publicados nos últimos 5 anos (20152020), sem restrição de idioma, aplicando sempre os critérios de inclusão e exclusão dos artigos. Onde foram incluídos todos os estudos primários publicados nos últimos 5 anos que relatam as atividades farmacológicas da espécie $M$. citrifolia, sendo esses estudos in vitro e in vivo; além disso, também foram recuperados artigos disponíveis no PubMed no mesmo período relatado acima, usando a string "Morinda citrifolia AND pharmacological activity", onde foram encontrados 92 artigos. Em relação a esses trabalhos, foram incluídos apenas artigos publicados e disponíveis integralmente nas bases de dados científicas 
citadas anteriormente. Após a leitura do título e resumo, o trabalho foi selecionado caso confirmada a sua relevância (Figura $1)$.

Após esse levantamento, foi feita uma segunda triagem onde os trabalhos foram lidos na íntegra, avaliando sempre os critérios de qualidade e, decidido junto aos outros membros da equipe quais artigos definitivamente iriam ser incluídos. O revisor fez uma síntese de cada um deles destacando sempre os pontos relevantes para a revisão. A extração dos dados foi feita de acordo com uma tabela, onde foram organizadas as seguintes informações: Título do artigo, autores, resumo, referência e a síntese dos resultados.

Figura 1. Fluxograma de seleção de artigos segundo as bases de dados.

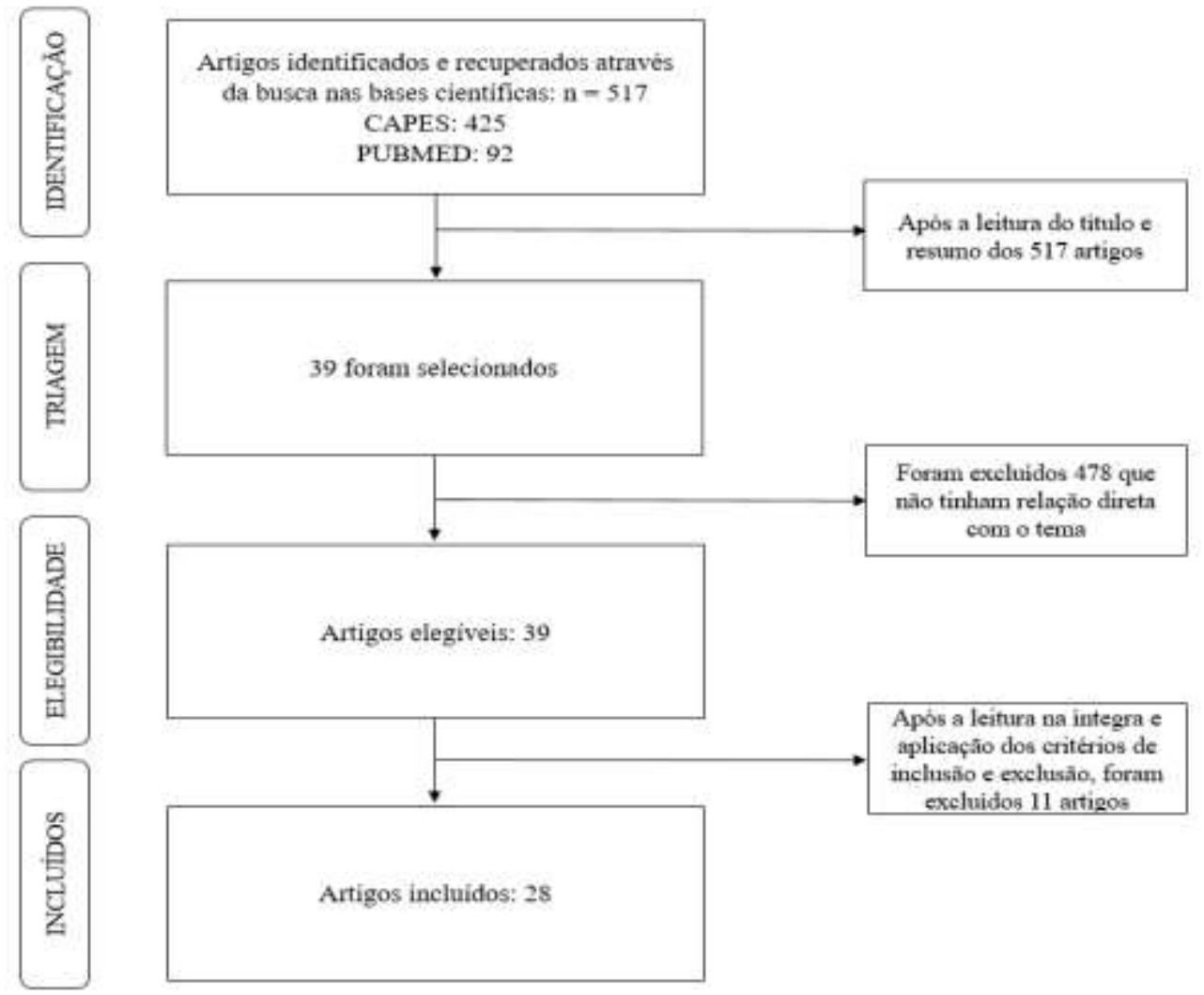

Fonte: Autores (2021).

\section{Resultados e Discussão}

Na busca realizada no Portal CAPES/MEC foram encontrados no total 425 artigos identificados na pesquisa inicial, sendo 206 artigos relacionados à primeira string e 219 artigos da segunda string, enquanto no PubMed foram recuperados 92 artigos. Após a leitura dos títulos e resumos foram excluídos 395 artigos do Periódicos da CAPES e 83 do PubMed, que não tinham relação direta com o tema da revisão integrativa.

No total, foram incluídos 28 artigos, publicados em 2015 (3 artigos), 2016 (8 artigos), 2017 (2 artigos), 2018 (5 artigos), 2019 (5 artigos) e 2020 (5 artigos). A respeito das partes da planta utilizadas, essas restringiram-se aos frutos (71,4\%), folhas $(21,4 \%)$, raízes $(7,1 \%)$ e sementes $(3,6 \%)$ (Tabela 1$)$.

Quanto à distribuição dos artigos por tema, nove $(32,1 \%)$ avaliaram a atividade antioxidante e anti-inflamatória, sendo 6 estudos in vivo (21,4\%) (Dussossoy, et al., 2016; Shalan, et al., 2016; Sousa, et al., 2018; Batista, et al., 2019; Yang, et al., 2019; Yang, et al., 2020), 2 in vitro e in vivo (7,1\%) (Chen, et al., 2018; Narasimhan, et al., 2019); e 1 in vitro (3,6\%) 
Research, Society and Development, v. 10, n. 4, e30210414149, 2021

(CC BY 4.0) | ISSN 2525-3409 | DOI: http://dx.doi.org/10.33448/rsd-v10i4.14149

(Ishibashi, et al., 2017). Em relação aos estudos que avaliaram a atividade antitumoral e citotoxicidade, 4 adotaram métodos in vitro (14,29\%) (Sharma, et al., 2015; Sukamporn et al., 2016; Wang, et al., 2019; Rajivgandhi, et al., 2020), e 1 utilizou a associação de estudos in vitro e in vivo (3,6\%) (Lim, et al., 2016). Para a atividade antimicrobiana houve pequeno predomínio de estudos in vivo $(7,1 \%)$ em relação ao in vitro (3,6\%) (Podar, et al., 2015; Ahmed, et al., 2015; Divia, et al., 2018), enquanto que para atividade antileishmania 2 estudos foram in vitro e in vivo (7,1\%) (Almeida-Souza, et al., 2016a; Almeida-Souza, et al., 2018) e 1 in vivo (3,6\%;) (Almeida-Souza, et al., 2016b). Outros três dos trabalhos foram sobre o efeito hipotensivo, hipoglicêmico e a diminuição da frequência cardíaca, in vivo, sendo dois estudos com humanos e um em animais (10,7\%) (Wigati, et al., 2017; Algenstaedt, Stumpenhagen \& Westendorf., 2018; Nowak, et al., 2019). Os demais artigos (17,9\%) avaliaram os efeitos cicatrizante, hepatoprotetor, tratamento da pancreatite aguda, atividade antilipêmica e citoproteção, todos realizados em modelos in vivo (Tabela 1) (Mhatre, et al., 2016; Jambocus, et al., 2017; Gadicherla, et al., 2019; Chong, et al., 2019; Trieu Ly, et al., 2020). 
Research, Society and Development, v. 10, n. 4, e30210414149, 2021

(CC BY 4.0) | ISSN 2525-3409 | DOI: http://dx.doi.org/10.33448/rsd-v10i4.14149

Tabela 1. Classificação dos artigos de acordo com os títulos, ano de publicação, atividade, partes do vegetal utilizadas e referências (2015-2020).

\begin{tabular}{|c|c|c|c|c|}
\hline Título & Ano de publicação & Atividade biológica & Partes utilizadas & Referências \\
\hline $\begin{array}{l}\text { Phytochemical Analysis and Wound-Healing Activity of Noni (Morinda } \\
\text { citrifolia) Leaf Extract }\end{array}$ & 2020 & Cicatrizante & Folhas & Trieu Ly et al. \\
\hline $\begin{array}{l}\text { Pulmonary anti-inflammatory effects and spasmolytic properties ofCosta } \\
\text { Rican noni juice (Morinda citrifolia L.) }\end{array}$ & 2016 & Anti-inflamatória & Frutos & $\begin{array}{l}\text { Dussossoy et } \\
\text { al. }\end{array}$ \\
\hline $\begin{array}{l}\text { Morinda citrifolia and Its Active Principle Scopoletin Mitigate Protein } \\
\text { Aggregation and Neuronal Apoptosis through Augmenting the DJ- } \\
\text { 1/Nrf2/ARE Signaling Pathway }\end{array}$ & 2019 & Antioxidante & Frutos & $\begin{array}{l}\text { Narasimhan et } \\
\text { al. }\end{array}$ \\
\hline $\begin{array}{l}\text { Neuroprotective effects of chloroform and aqueous fractions of noni juice } \\
\text { against t-Butyl hydroperoxide-induced oxidative damage in SH-SY5Y } \\
\text { cells }\end{array}$ & 2018 & Antioxidante & Frutos & Chen et al. \\
\hline $\begin{array}{l}\text { Alleviating effects of noni fruit polysaccharide on hepatic oxidative stress } \\
\text { and inflammation in rats under a high-fat diet and its possible mechanisms }\end{array}$ & 2020 & Antioxidante e anti-inflamatória & Frutos & Yang et al. \\
\hline $\begin{array}{l}\text { Therapeutic effects of noni fruit water extract and polysaccharide on } \\
\text { oxidate sstres and inflammation in mice under higt-fat diet. }\end{array}$ & 2019 & Antioxidante e anti-inflamatória & Frutos & Yang et al. \\
\hline $\begin{array}{l}\text { N-butanol extracts of Morinda citrifolia suppress advanced glycation end } \\
\text { products (AGE)-induced inflammatory reactions in endothelial cells } \\
\text { through its anti-oxidative properties }\end{array}$ & 2017 & Antioxidante e anti-inflamatória & Frutos & Ishibashi et al. \\
\hline $\begin{array}{l}\text { Polysaccharides derived from Morinda citrifolia } \text { Linn reduce } \\
\text { inflammatorymarkers during experimental colitis }\end{array}$ & 2019 & Antioxidante e anti-inflamatória & Frutos & Batista et al. \\
\hline $\begin{array}{l}\text { Chemical structure and anti-inflammatory effect of polysaccharide } \\
\text { extracted from Morinda citrifolia Linn (Noni) }\end{array}$ & 2018 & Antioxidante e anti-inflamatória & Frutos & Sousa et al. \\
\hline $\begin{array}{l}\text { Morinda citrifolia leaf enhanced performance by improving angiogenesis, } \\
\text { mitochondrial biogenesis, antioxidant, anti-inflammatory \& stress } \\
\text { responses }\end{array}$ & 2016 & Antioxidante e anti-inflamatória & Folhas & Shalan et al. \\
\hline $\begin{array}{l}\text { Anticancer Effects of Extracts from the Fruit of Morinda Citrifolia (Noni) } \\
\text { in Breast Cancer Cell Lines. }\end{array}$ & 2015 & Antitumoral & Frutos & Sharma et al. \\
\hline $\begin{array}{l}\text { Damnacanthal and its nanoformulation exhibit anti-cancer activity } \\
\text { viacyclin D1 down-regulation }\end{array}$ & 2016 & Antitumoral & Raízes & $\begin{array}{l}\text { Sukamporn et } \\
\text { al. }\end{array}$ \\
\hline $\begin{array}{l}\text { Comparison of Anthraquinones, Iridoid Glycosides and Triterpenoids } \\
\text { in Morinda officinalis and Morinda citrifolia Using UPLC/Q-TOF-MS } \\
\text { and Multivariate Statistical Analysis. }\end{array}$ & 2020 & Antitumoral & Raízes & Wang et al. \\
\hline $\begin{array}{l}\text { Metastasized lung cancer suppression by Morinda citrifolia (Noni) leaf } \\
\text { compared to Erlotinib via anti-inflammatory, endogenous antioxidant } \\
\text { responses and apoptotic gene activation }\end{array}$ & 2016 & Antitumoral & Folhas & Lim et al. \\
\hline
\end{tabular}


Research, Society and Development, v. 10, n. 4, e30210414149, 2021

(CC BY 4.0) | ISSN 2525-3409 | DOI: http://dx.doi.org/10.33448/rsd-v10i4.14149

\begin{tabular}{|c|c|c|c|c|}
\hline $\begin{array}{l}\text { Enhanced anti-cancer activity of chitosan loaded Morinda citrifolia } \\
\text { essential oil against A549 human lung cancer cells }\end{array}$ & 2020 & Antictumoral & Sementes & $\begin{array}{l}\text { Rajivgandhi et } \\
\text { al. }\end{array}$ \\
\hline $\begin{array}{l}\text { Hepatoprotective Effects of Morinda citrifolia Leaf Extract on } \\
\text { Ovariectomized Rats Fed with Thermoxidized Palm Oil Diet: Evidence at } \\
\text { Histological and Ultrastructural Level }\end{array}$ & 2019 & Hepatoprotetor & Folhas & $\begin{array}{l}\text { Chong; } \\
\text { Hussan } \\
\text { Othman. }\end{array}$ \\
\hline $\begin{array}{l}\text { Hypotensive Activity of Ethanolic Extracts of Morinda citrifolia L. } \\
\text { Leaves and Fruit in Dexamethasone-Induced Hypertensive Rat }\end{array}$ & 2017 & $\begin{array}{l}\text { Hipotensivo e diminuição da } \\
\text { frequência cardíaca }\end{array}$ & Folhas e frutos & Wigati et al. \\
\hline $\begin{array}{l}\text { Effects of Acute Consumption of Noni and Chokeberry Juices vs. Energy } \\
\text { Drinks on Blood Pressure, Heart Rate, and Blood Glucose in Young } \\
\text { Adults. }\end{array}$ & 2019 & $\begin{array}{ll}\text { Hipotensivo, hipoglicêmico e } \\
\text { diminuição } \\
\text { cardíaca }\end{array}$ & Frutos & Nowak et al. \\
\hline $\begin{array}{l}\text { Fruit Juice on the Blood Sugar Level and Other Serum Parameters in } \\
\text { Patients with Diabetes Type } 2 \text {. }\end{array}$ & 2018 & Hipoglicemiante & Frutos & $\begin{array}{l}\text { Algenstaedt, } \\
\text { et al. }\end{array}$ \\
\hline $\begin{array}{l}\text { Morinda citrifolia (Noni) fruit protects the exocrine pancreatic } \\
\text { dysfunction against L-arginine induced acute pancreatitis in rats }\end{array}$ & 2019 & Pancreatite aguda & Frutos & $\begin{array}{l}\text { Gadicherla et } \\
\text { al. }\end{array}$ \\
\hline $\begin{array}{l}\text { In vitro activity of Morinda citrifolia Linn. fruit juice against the axenic } \\
\text { amastigote form of Leishmania amazonensis and its hydrogen peroxide } \\
\text { induction capacity in BALB/c peritoneal macrophages. }\end{array}$ & 2018 & Leishmanicida & Frutos & $\begin{array}{l}\text { Almeida- } \\
\text { Souza et al. }\end{array}$ \\
\hline $\begin{array}{l}\text { Morinda citrifolia Linn. Reduces Parasite Load and Modulates Cytokines } \\
\text { and Extracellular Matrix Proteins in C57BL/6 Mice Infected with } \\
\text { Leishmania (Leishmania) amazonensis }\end{array}$ & $2016 a$ & Leishmanicida & Frutos & $\begin{array}{l}\text { Almeida- } \\
\text { Souza et al. }\end{array}$ \\
\hline $\begin{array}{l}\text { Ultrastructural Changes and Death of Leishmania infantum Promastigotes } \\
\text { Induced by Morinda citrifolia Linn. Fruit (Noni) Juice Treatment }\end{array}$ & $2016 b$ & Leishmanicida & Frutos & $\begin{array}{l}\text { Almeida- } \\
\text { Souza et al. }\end{array}$ \\
\hline $\begin{array}{l}\text { Morinda citrifolia L. leaf extract prevent weight gain in Sprague-Dawley } \\
\text { rats fed a high fat diet }\end{array}$ & 2017 & Antilipêmica & Folhas & $\begin{array}{l}\text { Jambocus et } \\
\text { al. }\end{array}$ \\
\hline $\begin{array}{l}\text { A comparative evaluation of Morinda citrifolia, green tea polyphenols, } \\
\text { and Triphala with } 5 \% \text { sodium hypochlorite as an endodontic irrigant } \\
\text { against Enterococcus faecalis : An in vitro study }\end{array}$ & 2018 & $\begin{array}{l}\text { Antimicrobiana como irrigante } \\
\text { odontológico }\end{array}$ & Frutos & Divia et al. \\
\hline $\begin{array}{l}\text { In vivo antimicrobial efficacy of } 6 \% \text { Morinda citrifolia, Azadirachta } \\
\text { indica, and } 3 \% \text { sodium hypochlorite as root canal irrigants }\end{array}$ & 2015 & $\begin{array}{l}\text { Antimicrobiana como irrigante } \\
\text { odontológico }\end{array}$ & Frutos & Podar et al. \\
\hline $\begin{array}{l}\text { Antibacterial efficacy and effect of Morinda citrifolia L. mixed with } \\
\text { irreversible hydrocolloid for dental impressions: A randomized controlled } \\
\text { trial. }\end{array}$ & 2015 & $\begin{array}{l}\text { Antimicrobiana como irrigante } \\
\text { odontológico }\end{array}$ & Frutos & Ahmed et al. \\
\hline $\begin{array}{l}\text { Protective effect of Morinda citrifolia L. (fruit extract) on methotrexate- } \\
\text { induced toxicities-hematological and biochemical studies }\end{array}$ & 2016 & $\begin{array}{lrr}\begin{array}{l}\text { Efeito protetor das } \\
\text { adversas reações } \\
\text { metotrexato }\end{array} & \text { induzidas } & \text { por } \\
\end{array}$ & Frutos & $\begin{array}{l}\text { Mhatre } \\
\text { Marar. }\end{array}$ \\
\hline
\end{tabular}

Fonte: Autores (2021) 


\subsection{Atividades farmacológicas avaliadas}

\subsubsection{Atividades antioxidante e anti-inflamatória}

Ratos tratados com extrato aquoso das folhas de M. citrifolia foram submetidos ao ensaio do nado forçado (exaustão) e, posteriormente, foram realizadas avaliações relacionadas ao estresse oxidativo, metabolismo, liberação de neurotransmissores e angiogênese. Em animais tratados com $200 \mathrm{mg} / \mathrm{Kg}$, foi observado melhoras nas respostas antioxidantes dos mamíferos (níveis de MDA, GSH e SOD2); o controle dos nutrientes do tecido (glicose) e do metabólito (lactato); a regulação do hormônio do estresse (cortisol); expressões de neurotransmissores (dopamina, noradrenalina, serotonina); angiogênese do músculo esquelético (VEGFA) e energia e biogênese mitocondrial (via PGC, UCP3, NRF2, AMPK, MAPK1 e CAMK4). O extrato ergogênico ajudou a retardar a fadiga, aumentando a produção, regulação e eficiência de energia, o que sugere benefícios para atividades físicas e recuperação de doenças (Tabela 2) (Shalan, et al., 2016).

Produtos finais de glicação avançada (AGEs) causam danos às células endoteliais (CE), um start para a aterosclerose por meio da interação com um receptor AGE (RAGE). Os efeitos dos extratos de n-butanol de M. citrifolia na geração de espécies reativas de oxigênio (ROS) e reações inflamatórias em CEs de veia umbilical humana expostos a AGE (HUVECs) foram avaliados. A adesão de células THP-1 a HUVECs foi medida após 2 dias de incubação de albumina de soro bovino de AGE, na presença ou ausência de extratos de n-butanol $(670 \mathrm{mg} / \mathrm{ml})$. O tratamento com o extrato inibiu a geração de ROS induzida pela interação entre AGE e RAGE, consequentemente suprimiu as reações inflamatórias. Os AGEs aumentaram significativamente a adesão de células THP-1 monocíticas a HUVECs, entretanto a adição do extrato reduziu este efeito. Em síntese, o extrato de N-butanol pode suprimir as reações inflamatórias induzidas por AGE em HUVECs por meio de suas propriedades antioxidantes através do bloqueio da interação de AGEs com RAGE (Tabelas 2, 3) (Ishibashi, et al., 2017).

$\mathrm{O}$ estresse oxidativo tem maior probabilidade de causar danos às células neuronais e mediar alguns distúrbios neurodegenerativos. Visando avaliar o potencial na prevenção dos danos ocasionados pelo estresse oxidativo, em células SHSY5Y, essas foram tratadas com hidroperóxido de terc-butila (TBHP), com a fração clorofórmica (FC) e a fração aquosa (FA) de M. citrifolia. Os resultados demonstraram redução da citotoxicidade induzida por TBHP, supressão da geração de espécies reativas de oxigênio, despolarização da membrana mitocondrial e características apoptóticas. FC e FA restauraram a atividade da enzima antioxidante celular; expressão regulada positivamente de heme oxigenase-1, catalase e superóxido dismutase-1; e aumentou o acúmulo nuclear do fator 2 relacionado ao fator nuclear eritróide 2 (Nrf2). O potencial antioxidante e de neuroproteção da FC pode ser responsável por seu alto conteúdo total de fenólicos e flavonoides, enquanto a FA pode ser rica em polissacarídeos. Esses resultados sugerem que FC e FA exibem defesa antioxidante por meio da suprarregulação de Nrf2 junto com antioxidantes endógenos e reduzem a apoptose por meio da inibição da via mitocondrial para proteger as células SH-SY5Y danificadas por TBHP (Tabela 2) (Chen, et al., 2018).

Em um estudo experimental de Colite Ulcerativa (CU) induzida por ácido acético em camundongos, foi avaliado o efeito de Polissacarídeos (PLS) extraídos de $M$. citrifolia na dosagem de 0,1, 0,3 e 3,0 mg/kg, por via intraperitoneal. As amostras de tecido colônico foram coletadas para análise bioquímica (mieloperoxidase (MPO), glutationa (GSH), malondialdeído (MDA), nitrato/nitrito $\left(\mathrm{NO}_{3} / \mathrm{NO}_{2}\right)$, e óxido nítrico induzível (iNOS). O tratamento com PLS reduziu a atividade de MPO e os níveis de GSH, MDA, $\mathrm{NO}_{3} / \mathrm{NO}_{2}$ (Tabela 2) (Batista et al. 2019).

Um outro estudo avaliou a atividade antioxidante do polissacarídeo de M. citrifolia, in vivo, utilizando modelos de indução da inflamação pela carragenina, teste de contorção abdominal induzida por ácido acético e teste da formalina. Quando os animais foram tratados com $10 \mathrm{mg} / \mathrm{kg}$ do polissacarídeo, observou-se redução dos níveis de glutationa e mieloperoxidase (Tabela 2) (Sousa, et al., 2018). 
Research, Society and Development, v. 10, n. 4, e30210414149, 2021

(CC BY 4.0) | ISSN 2525-3409 | DOI: http://dx.doi.org/10.33448/rsd-v10i4.14149

Ratos foram submetidos a uma dieta rica em lipídeos e tratados com polissacarídeos isolados de M. citrifolia (50, 100 e $200 \mathrm{mg} / \mathrm{kg}$ ). Na dose de 100 a $200 \mathrm{mg} / \mathrm{kg}$ houve redução dos níveis das enzimas hepáticas (AST e ALT) e o aumento de enzimas com capacidade antioxidante (Capacidade Antioxidante Equivalente ao Trolox, Superóxido dismutase, Glutationa Peroxidase, Fator Nuclear Eritroide 2 relacionado ao fator 2), assim como a diminuição do TNF- $\alpha$ a e da IL-1 $\beta$, se mostrando um polissacarídeo promissor para previnir o estresse oxidativo e a inflamação (Tabelas 2, 3) (Yang, et al., 2019).

A atividade do extrato da fruta de $M$. citrifolia e da escopoletina (princípio ativo extraído da espécie) frente a Doença de Parkinson (DP) induzida por rotenona foi avaliada. No estudo foi possível observar que o extrato atenuou o estresse oxidativo induzido por rotenona em animais, diminuindo os níveis de óxido nítrico (NO), diminuindo a peroxidação lipídica (LPO) e carbonilas protéicas (CP). Também foi observado a redução de $\alpha$-sinucleína um marcador primário no processo de agregação de proteínas - que pode ocorrer durante o estresse oxidativo. Além disso, o tratamento com o extrato dos frutos regulou positivamente a via Nrf2, que foi regulada negativamente na indução da DP por rotenona. Em relação ao tratamento com escopoletina houve uma atenuação do apoptose induzido por rotenona em células SH-SY5Y e, também, houve um aumento nos níveis nucleares de Nrf2 que está relacionado com a resistência da morte celular, levando a atenuação do estresse oxidativo que pode ser benéfico na DP (Tabela 2) (Narasimhan, et al., 2019). 
Research, Society and Development, v. 10, n. 4, e30210414149, 2021

(CC BY 4.0) | ISSN 2525-3409 | DOI: http://dx.doi.org/10.33448/rsd-v10i4.14149

Tabela 2. Atividade antioxidante de Morinda citrifolia.

\begin{tabular}{|c|c|c|c|c|}
\hline \multicolumn{2}{|l|}{ Amostras } & Modelo & Resultados obtidos & Referência \\
\hline \multicolumn{2}{|l|}{ EAF } & Nado forçado & $\begin{array}{l}\text { Redução dos níveis de MDA/Cortisol e melhora nos níveis de GSH/SOD2 nas doses de } \\
200 \mathrm{mg} / \mathrm{kg} \text { e } 400 \mathrm{mg} / \mathrm{kg}\end{array}$ & Shalan, et al., 2016 \\
\hline \multicolumn{2}{|l|}{ EBFr } & $\begin{array}{l}\text { Células endoteliais da veia } \\
\text { umbilical humana }\end{array}$ & $\begin{array}{l}670 \mathrm{ng} / \mathrm{ml} \text { impediu os produtos finais de glicação avançada (AGEs), consequentemente, a } \\
\text { produção de ERO }\end{array}$ & Ishibashi, et al., 2017 \\
\hline \multirow[b]{2}{*}{ Suco do fruto } & FC & \multirow{2}{*}{$\begin{array}{lr}\text { Estresse } & \text { oxidativo em } \\
\text { células } & \text { SH-SY5Y } \\
\text { induzido por TBHP }\end{array}$} & \multirow{2}{*}{$\begin{array}{l}\text { O tratamento com as frações aquosa e clorofórmica restauraram a atividade das enzimas } \\
\text { antioxidantes SOD-1, CAT, GPx e GR conferindo proteção às células SH-SY5Y }\end{array}$} & \multirow[b]{2}{*}{ Chen, et al., 2018} \\
\hline & FA & & & \\
\hline \multicolumn{2}{|l|}{ NFP } & $\begin{array}{l}\text { Edema de pata induzido } \\
\text { por carragenina }\end{array}$ & 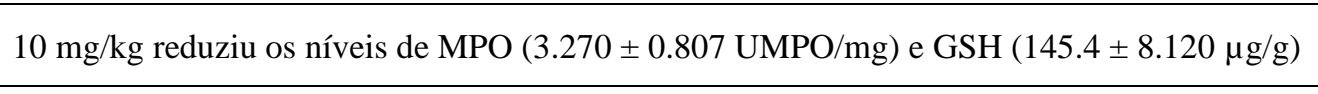 & Sousa, et al., 2018 \\
\hline \multicolumn{2}{|l|}{ NFP } & \multirow[t]{2}{*}{ HFD em ratos } & $\begin{array}{l}\text { Os níveis hepáticos de MDA foram menores do que no grupo HFD, houve aumento de } \\
\text { TEAC, SOD e GSH-Px. Nos grupos em que foram administrados } 100 \text { e } 200 \mathrm{mg} / \mathrm{kg} \text { do } \\
\text { extrato tiveram níveis maiores de Nrf2 do que o grupo HFD }\end{array}$ & \multirow[t]{2}{*}{ Yang, et al., 2019} \\
\hline \multicolumn{2}{|l|}{ EAFr } & & $\begin{array}{l}\text { Os níveis hepáticos de MDA foram menores do que no grupo HFD, houve aumento de } \\
\text { TEAC, porém o extrato não teve efeito na SOD e GSH-Px }\end{array}$ & \\
\hline \multicolumn{2}{|l|}{ PFN } & $\begin{array}{l}\text { Dano intestinal induzido } \\
\text { por ácido acético em } \\
\text { camundongos }\end{array}$ & $\begin{array}{l}3 \mathrm{mg} / \mathrm{kg} \text { do polissacarídeo reduziu os níveis de } \mathrm{MPO}, \mathrm{MDA} \text { e } \mathrm{NO}_{3} / \mathrm{NO}_{2} \text {. Por outro lado, } \\
\text { aumentou os de GSH em comparação ao grupo que tinha colite }\end{array}$ & Batista, et al., 2019 \\
\hline \multicolumn{2}{|l|}{ EAEFr } & Ratos Sprangue-Dawley & $\begin{array}{l}\text { Após a administração do extrato houve aumento das atividades de SOD (36\%), CAT, GST e } \\
\text { prevenindo também o estresse oxidativo através da sinalização de DJ-1/Nrf2 }\end{array}$ & $\begin{array}{l}\text { Narasimhan, et al., } \\
2019\end{array}$ \\
\hline \multicolumn{2}{|l|}{ PFN } & HFD em ratos & $\begin{array}{l}100 \mathrm{mg} / \mathrm{kg} \text { do extrato administrado durante } 5 \text { semanas diminuiu os níveis de MAD e } \\
\text { aumentou, os níveis de TEAC, SOD, GSH-Px e CAT }\end{array}$ & Yang, et al., 2020 \\
\hline
\end{tabular}

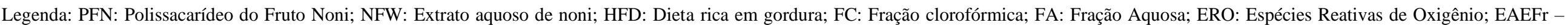

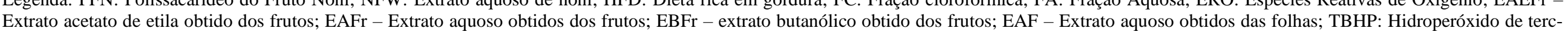

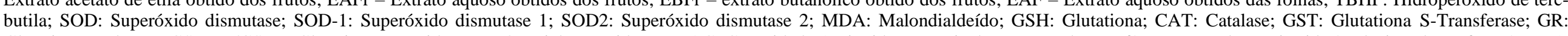

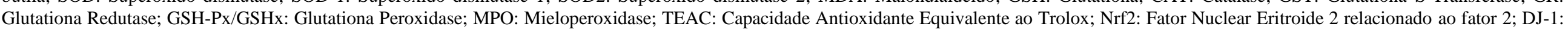
Proteína desglicase DJ-1; $\mathrm{NO}_{3}$ : Nitrato; $\mathrm{NO}_{2}$ : Nitrito. Fonte: Autores (2021). 
Research, Society and Development, v. 10, n. 4, e30210414149, 2021

(CC BY 4.0) | ISSN 2525-3409 | DOI: http://dx.doi.org/10.33448/rsd-v10i4.14149

Além da avaliação da atividade antioxidante, muitos trabalhos avaliaram a atividade anti-inflamatória da M. citrifolia. Um estudo avaliou o nível de citocinas em ratos submetidos ao nado forçado tratados com extrato aquoso da espécie e observou que animais tratados com $200 \mathrm{mg} / \mathrm{kg}$ regulou positivamente aumentando a expressão de mRNA das citocinas antiinflamatórias IL-4 e IL-10 tanto no fígado quanto no músculo dos animais e aumentou o fator de crescimento endotelial vascular A, sugerindo haver efeito anti-inflamatório (Tabela 3) (Shalan, et al., 2016).

Outro estudo avaliou o efeito anti-inflamatório, em modelo de inflamação crônica pulmonar sensibilizado com ovalbumina em animais tratados (via oral e intraperitoneal) com o suco de M. citrifolia. Houve redução da inflamação (dose $\mathrm{IP}=2,17 \mathrm{~mL} / \mathrm{kg}$ e $\mathrm{VO}=4,55 \mathrm{~mL} / \mathrm{kg}$ ) com diminuição do número de células inflamatórias no pulmão (macrófagos menos 20 26\%, linfócitos menos 58-34\%, eosinófilos menos 53-30\%, neutrófilos menos 70-28\%, respectivamente), efeito de eliminação de NO dependente da dose, inibição (até 90\%) dos espasmos induzidos por cálcio e colinérgicos no modelo de segmentos do jejuno (Tabela 3) (Dussossoy, et al., 2016).

Ainda foi avaliado o potencial anti-inflamatório do extrato de N- butanol na aterosclerose. Sabe-se que ICAM-1 (Intercellular Adhesion Molecule 1) estimula o recrutamento e a adesão de células inflamatórias às células endoteliais, o que pode promover reações inflamatórias na aterosclerose. Além disso, a atividade fibrinolítica atenuada pelo aumento dos níveis de PAI-1 (inibidor do ativador de plasminogênio tipo 1) está associada ao aumento do risco de aterotrombose e doença cardiovascular em pacientes diabéticos (Takenaka, et al., 2006). Dado que os AGEs podem induzir a expressão dos genes ICAM-1 e PAI-1 em HUVECs via geração de ROS por meio da interação com RAGE (Matsui, et al., 2011; Matsui, et al., 2016), o bloqueio da interação AGE-RAGE por extratos de n-butanol pode ser um mecanismo central por que poderiam proteger contra lesão de células endoteliais induzida por AGE, tornando-se assim um alvo terapêutico para doença cardiovascular aterosclerótica. Os iridóides presentes na espécie bloqueiam as reações inflamatórias em células mesangiais expostas a AGE e rins de camundongos diabéticos (Xu, et al., 2006; Yokozama, et al., 2010). Seria interessante examinar se os iridoides podem realmente inibir a ligação dos AGEs ao RAGE in vitro (Tabela 3) (Ishibashi, et al., 2017).

O polissacarídeo (PLS) de M. citrifolia foi testado no edema de pata induzido por $\lambda$-carragenina, sendo o melhor efeito anti-inflamatório na dose do PLS a $10 \mathrm{mg} / \mathrm{kg}$ com redução no edema ao longo da duração do efeito testado quando comparados com animais que receberam apenas o agente inflamatório. Os dados histopatológicos do tecido da pata após o tratamento com PLS mostraram a diminuição da lesão inflamatória. O tratamento com PLS foi eficaz em ambas as fases do edema de pata induzido por carragenina, nas quais promoveu redução significativa no volume da pata. Em outros experimentos foram administrados dextrano $(500 \mu \mathrm{g} / \mathrm{kg}$ ), histamina, serotonina e bradicinina, sendo observado o edema na pata após 30 minutos. O tratamento com PLS antes da administração desses agentes, reduziu significativamente o pico máximo do edema em 30 minutos, o PLS diminui o edema da pata induzido por dextrana dependente do aumento da permeabilidade vascular induzido por mediadores rápidos, como histamina e serotonina. Outro importante mediador inflamatório que também teve seu efeito antagonizado pelo PLS foi a bradicinina (Sousa, et al., 2018). A atividade do PLS na redução do edema de pata promovido por diferentes mediadores corrobora com a redução da primeira fase do edema induzido pela carragenina (Florentino et al., 2017; Sousa, et al., 2018). A fim de avaliar como o PLS atua na redução da segunda fase do edema induzido por carragenina, analisou-se a migração de neutrófilos para o sítio inflamatório por meio de observações diretas e indiretas, foi possível observar que o PLS diminuiu a migração de leucócitos para a cavidade peritoneal dos camundongos para 46,41\% (Tabela 3) (Sousa, et al., 2018).

A dieta rica em gordura pode induzir acúmulo de lipídios e estresse oxidativo no fígado, desencadeando inflamação. E estes animais, quando tratados com polissacarídeos tiveram os níveis hepáticos de IL- 6 e TNF- $\alpha$ ligeiramente maiores que as do grupo controle normal, indicando que ocorreu certo grau de inflamação, porém houve atenuação da inflamação em 
Research, Society and Development, v. 10, n. 4, e30210414149, 2021

(CC BY 4.0) | ISSN 2525-3409 | DOI: http://dx.doi.org/10.33448/rsd-v10i4.14149

camundongos sob dieta rica em gordura (Yang, et al., 2019). Citocinas pró-inflamatórias, como TNF- $\alpha$, IL-1 $\beta$ e IL-6, são elevadas em camundongos obesos, enquanto citocina anti-inflamatória IL-10 é reduzida (Feuerer, et al., 2009; Wang, et al., 2019). O tratamento com NFP (100 mg/kg) inibiu efetivamente os níveis de TNF- $\alpha$ e IL-1 $\beta$ no soro, mas aumentou o nível sérico de IL-10. Além disso, foram medidos os níveis de expressão relativa de mRNA de TNF- $\alpha$, IL-1 $\beta$ e IL-10 no fígado. Comparado com o grupo controle, o grupo HFD apresentou aumento dos níveis de expressão relativa do mRNA de TNF- $\alpha$, IL$1 \beta$ e IL-10 no fígado. Em comparação com o HFD grupo, a administração de PLS diminuiu os níveis de expressão relativa do mRNA hepático de TNF- $\alpha$, IL-1 $\beta$ e IL-10, que foram basicamente semelhantes ao grupo controle (Tabela 3) (Yang, et al., 2020).

Outro estudo avaliou a atividade dos polissacarídeos em marcadores inflamatórios da colite ulcerativa induzida por ácido acético. Os animais em teste que foram tratados intraperitonealmente com polissacarídeos extraídos do noni na dosagem de 0,1, 0,3 e 3,0 mg/Kg mostraram redução significativa em pontuações macroscópicas, microscópicas e diminuiu o peso úmido do cólon. Além disso, houve uma redução na atividade da Mieloperoxidase (MPO), nos níveis de Glutationa (GSH) e Malondialdeído (MDA), redução na concentração de nitrato e nitrito $\left(\mathrm{NO}_{3} / \mathrm{NO}_{2}\right)$ no tecido do colón, citocinas próinflamatórias e a expressão de ciclooxigenase (COX-2) também foram reduzidas, demonstrando um efeito anti-inflamatório (Tabela 3) (Batista, et al., 2019). 
Research, Society and Development, v. 10, n. 4, e30210414149, 2021

(CC BY 4.0) | ISSN 2525-3409 | DOI: http://dx.doi.org/10.33448/rsd-v10i4.14149

Tabela 3. Atividade anti-inflamatória de Morinda citrifolia.

\begin{tabular}{|c|c|c|c|}
\hline Amostras & Modelo & Resultados obtidos & Referência \\
\hline EAF & Natação com peso em ratos & $\begin{array}{l}200 \mathrm{mg} / \mathrm{kg} \text { do extrato regulou positivamente a produção de IL-4 e IL-10 tanto nos músculos } \\
\text { quanto no fígado }\end{array}$ & $\begin{array}{l}\text { Shalan, et al., } \\
2016\end{array}$ \\
\hline \multirow[b]{2}{*}{ Suco do fruto } & $\begin{array}{l}\text { Administração oral em ratos marrons com } \\
\text { inflamação pulmonar induzida por OVA }\end{array}$ & $\begin{array}{l}4,55 \mathrm{ml} / \mathrm{kg} \text { - diminuiu a formação de macrófagos (20\%), linfócitos (58\%), eosinófilos (53\%) e } \\
\text { neutrófilos }(70 \%)\end{array}$ & \multirow[b]{2}{*}{$\begin{array}{l}\text { Dussossoy, et al., } \\
2016\end{array}$} \\
\hline & $\begin{array}{l}\text { Administração intraperitoneal em ratos } \\
\text { marrons com inflamação pulmonar induzida } \\
\text { por OVA }\end{array}$ & $\begin{array}{l}2,17 \mathrm{ml} / \mathrm{kg} \text { - diminuiu a formação de macrófagos (26\%), linfócitos (34\%), eosinófilos (30\%) e } \\
\text { neutrófilos (28\%) }\end{array}$ & \\
\hline EBFr & células endoteliais da veia umbilical humana & $\begin{array}{l}670 \text { ng/kg bloqueou a produção de ERO suprimindo reações inflamatórias induzidas por AGE, } \\
\text { RAGE, ICAM-1 e PAI-1 }\end{array}$ & $\begin{array}{l}\text { Ishibashi, et al., } \\
2017\end{array}$ \\
\hline NFP & \multirow{2}{*}{ HFD em ratos } & \multirow{2}{*}{$\begin{array}{l}\text { Houve diminuição da inflamação, uma vez que os níveis de IL-6 e TNF- } \alpha \text { foram semelhantes ao } \\
\text { do grupo controle }\end{array}$} & \multirow{2}{*}{$\begin{array}{l}\text { Yang, et al., } \\
2019\end{array}$} \\
\hline NFW & & & \\
\hline NFP & $\begin{array}{l}\text { Edema de pata induzido por diferentes } \\
\text { mediadores inflamatórios }\end{array}$ & $\begin{array}{l}10 \mathrm{mg} / \mathrm{kg} \text { administrado por via intraperitoneal reduziu o edema em ratos que receberam } \\
\text { detrexana }(0,022 \pm 0,002 \mathrm{~mL}) \text {, serotonina }(0,035 \pm 0,002 \mathrm{~mL}) \text {, histamina }(0,036 \pm 0,003 \mathrm{~mL}) \text { e } \\
\text { bradicinina }(0,023 \pm 0,004 \mathrm{~mL})\end{array}$ & Sousa, et al., 2018 \\
\hline $\begin{array}{l}\text { Polissacarídeo } \\
\text { dos frutos do } \\
\text { Noni }\end{array}$ & $\begin{array}{l}\text { Dano intestinal induzido por ácido acético em } \\
\text { camundongos }\end{array}$ & $\begin{array}{l}\text { Foi observado efeito anti-inflamatório nos animais tratados com o polissacarídeo nas } \\
\text { concentrações } 0,1,0,3 \text { e } 3,0 \mathrm{mg} / \mathrm{kg} \text {, com atividade máxima na concentração } 3,0 \mathrm{mg} / \mathrm{kg}\end{array}$ & $\begin{array}{l}\text { Batista, et al., } \\
2019\end{array}$ \\
\hline NFP & HFD em ratos & $\begin{array}{l}100 \mathrm{mg} / \mathrm{kg} \text { do extrato administrado durante } 5 \text { semanas inibiu a produção de TNF- } \alpha(\mathrm{p}>0,01) \text { e } \\
\mathrm{IL}-1 \beta(\mathrm{p}<0,05) \text { e aumentou os níveis séricos de IL- } 10(\mathrm{p}<0,01)\end{array}$ & Yang, et al., 2020 \\
\hline
\end{tabular}

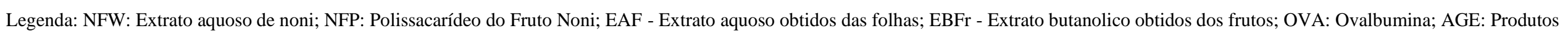
finais de glicação avançada; RAGE: Receptor multi-ligante da AGE; ICAM-1: Molécula de adesão intercelular-1; PAI-1: Inibidor do Ativador do Plasminogênio tipo 1; ERO: Espécies Reativas de Oxigênio; TNF- $\alpha$ : Fator de Necrose Tumoral alfa; IL-1 $\beta$ : Interleucina-1 $\beta$; IL-4: Interleucina-4; IL-6: Interleucina-6; IL-10: Interleucina-10. Fonte: Autores (2021). 


\subsubsection{Atividade antitumoral}

Diferentes frações da fruta de M. citrifolia foram testadas em linhagens tumorais MCF-7, MDA-MB-231 (adenocarcinoma de mama) e não tumoral HEK-293 (Rim embrionário humano). Destes, o extrato de acetato de etila mostrouse mais ativo, inibindo a proliferação das linhas celulares MCF-7 $\left(\mathrm{CI}_{50}=25 \mu \mathrm{g} / \mathrm{mL}\right)$, MDA-MB-231 $\left(\mathrm{CI}_{50}=35 \mu \mathrm{g} / \mathrm{mL}\right)$ e HEK-293 $\left(\mathrm{CI}_{50}=60 \mu \mathrm{g} / \mathrm{mL}\right)$. Este extrato elevou a taxa de apoptose em MCF-7 e MDA-MB-231 e interrompeu o ciclo celular na fase G1 / S em MCF-7 e G0 / G1 em MDA-MB-231. Esse efeito também pode ser dado devido a ativação da caspase-8 que induz o dano mitocondrial (Tabela 4) (Sharma, et al., 2015).

Os efeitos do extrato das folhas de M. citrifolia (Noni) inibiu a proliferação celular e induziu apoptose em células A549 $\left(\mathrm{CI}_{50}=23,47 \mu \mathrm{g} / \mathrm{mL}\right)$ e células de carcinoma pulmonar Lewis (LL2) de camundongo $\left(\mathrm{CI}_{50}=5,50 \mu \mathrm{g} / \mathrm{mL}\right)$ in vitro, interrompendo o ciclo de células tumorais nas fases G0/G1 e aumentou significativamente a caspase-3/caspase-8 sem alterar os níveis da caspase-9. O extrato não mostrou toxicidade em células pulmonares MRC5 normais. Câncer de pulmão de células não pequenas (NSCLC) foram tratadas com extrato de folha de M. citrifolia e comparados com Erlotinibe por 21 dias. Houve aumento dos genes TRP53 pró-apoptóticos, regulou negativamente os genes pró-tumorigênese (BIRC5, JAK2 / STAT3 / STAT5A) nos tumores de camundongos, aumentou significativamente a expressão de IL-4, IL-10 e NR3C1 anti-inflamatórios no pulmão metastizado e tecidos de câncer hepático, aumentando as respostas antioxidantes dependentes de NFE2L2 contra lesões oxidativas. Houve supressão da inflamação e o edema, e regulou positivamente as respostas antioxidantes endógenas e os genes apoptóticos para suprimir o câncer. O extrato de $300 \mathrm{mg} / \mathrm{kg}$ foi mais eficaz do que $50 \mathrm{mg} / \mathrm{kg}$ de Erlotinibe para a maioria dos parâmetros medidos (Lim, et al., 2016). Também o óleo essencial desta espécie foi ativo em câncer pulmonar (Tabela 4) (Rajivgandhi, et al., 2020)

Damnacanthal é uma antraquinona isolada da raiz de M. citrifolia que atua na apoptose. Também, inibi o crescimento de várias linhagens celulares tumorais (HCT-116, HT-29, MCF-7 e PC-3), de forma dependente de concentração e tempo, através da diminuição da expressão proteica de ciclina D1. Entretanto, o damnacanthal não altera o mRNA de ciclina D1, em vez disso, diminui a quantidade de expressões de ciclina D1 no nível pós-translacional através dos sítios envolvidos na lise dessa proteína, que desempenham um papel fundamental na sua degradação. Esta antraquinona, inibiu o crescimento de células HCT-116 (CI $\left.\mathrm{C}_{50}=10 \mu \mathrm{M}\right), \mathrm{HT}-29\left(\mathrm{CI}_{50}=50 \mu \mathrm{M}\right)$, MCF-7 $\left(\mathrm{CI}_{50}=50 \mu \mathrm{M}\right)$ e PC-3 (CI $\left.50=50 \mu \mathrm{M}\right)$ (Sukamporn, et al., 2016) (Tabela 4) e se considera uma molécula promissora para a atividade antitumoral quando $\mathrm{CI}_{50} \leq 30 \mu \mathrm{g} / \mathrm{mL}$ (Sarmento, 2016).

Extrato metanólico das raízes de $M$. citrifolia foi submetido ao ensaio CCK-8 para avaliar sua citotoxicidade em células hepáticas (célula normal: LO2; tumorais: HepG2, SMMCH771). Os resultados sugerem que o aumento do tempo de exposição das células ao extrato contribui para a citotoxicidade. Além disso, foi utilizado um ensaio de formação de colônias para avaliar o impacto a longo prazo deste extrato para as células. Os resultados mostraram que em maiores concentrações do extrato houve um aumento da proliferação celular de células LO2, porém ocorreu uma inibição da proliferação celular de células HepG2 e SMMCH771. Assim, sugere-se que este extrato não foi citotóxico para células normais, e até promoveu sua proliferação, porém apresentou citotoxicidade para às células tumorais (Tabela 4) (Wang, et al., 2019). 
Research, Society and Development, v. 10, n. 4, e30210414149, 2021

(CC BY 4.0) | ISSN 2525-3409 | DOI: http://dx.doi.org/10.33448/rsd-v10i4.14149

Tabela 4. Atividade antitumoral de Morinda citrifolia e índice de seletividade.

\begin{tabular}{|c|c|c|c|c|c|c|}
\hline Amostras & Atividade antit & & Citotoxici & & IS & Referência \\
\hline \multirow{5}{*}{ EEFr* } & Células & $\mathbf{C I}_{50}$ & Células & $\mathrm{CC}_{50}(\mu \mathrm{g} / \mathrm{mL})$ & & \\
\hline & MCF-7 & $25 \mu \mathrm{g} / \mathrm{mL}$ & \multirow{2}{*}{ HEK-293 } & \multirow{2}{*}{60} & 2,4 & \multirow{2}{*}{ Sharma, et al., 2015} \\
\hline & MDA-MB-231 & $35 \mu \mathrm{g} / \mathrm{mL}$ & & & 1,7 & \\
\hline & LL2 & $5,50 \mu \mathrm{g} / \mathrm{mL}$ & - & - & - & \multirow{2}{*}{ Lim, et al., 2016} \\
\hline & A549 & $23 \mu \mathrm{g} / \mathrm{mL}$ & - & - & - & \\
\hline OES* & A549 & $40 \mu \mathrm{g} / \mathrm{mL}$ & - & - & - & $\begin{array}{l}\text { Rajivgandhi, et al., } \\
2020\end{array}$ \\
\hline \multirow{4}{*}{ AIR* } & HCT-116 & $10 \mu \mathrm{M}$ & - & - & - & \multirow{4}{*}{$\begin{array}{l}\text { Sukamporn, et al., } \\
2016\end{array}$} \\
\hline & HT-29 & $50 \mu \mathrm{M}$ & - & - & - & \\
\hline & MCF-7 & $50 \mu \mathrm{M}$ & - & - & - & \\
\hline & PC-3 & $50 \mu \mathrm{M}$ & - & - & - & \\
\hline \multirow{2}{*}{ EMR** } & HepG2 & $100 \mu \mathrm{g} / \mathrm{mL}$ & \multirow{2}{*}{ LO2 } & \multirow{2}{*}{100} & 1 & \multirow{2}{*}{ Wang, et al., 2019} \\
\hline & SMMCH771 & $100 \mu \mathrm{g} / \mathrm{mL}$ & & & 1 & \\
\hline
\end{tabular}

Legenda: $\mathrm{CI}_{50}$ : Concentração Inibitória de 50\% dos parasitas; $\mathrm{CC}_{50}$ : Concentração citotóxica de 50\% das células; Índice de Seletividade; (IS)=CC $50 / \mathrm{CI}_{50}$; Índice de Seletividade (IS) > 10- seletivo. EEFr: Extrato Etanolico obtido dos frutos; OES: Óleo Essencial obtido das sementes; AIR: Antraquinona Isolada das Raízes; EMR: Extrato metanólico obtido das raízes; *Ensaio de viabilidade celular (MTT ou DMSO); ** Cell Couting Kit-8. Fonte: Autores (2021). 


\subsubsection{Atividade antileishmania}

As atividades antipromastigota e amastigota do extrato obtido das frutas de $M$. citrifolia foram analisadas, bem como as alterações ultraestruturais nos promastigotas de Leishmania infantum. Este extrato apresentou um baixo potencial antipromastigota e antiamastigota, também não foi citotóxico. Entretanto, a análise em microscopia eletrônica de transmissão mostrou vacuolização citoplasmática, inclusão lipídica, aumento da atividade de excitose e vesículas autofagossas em promastigota de L. infantum (Almeida-Souza, et al. 2016b), logo estudos adicionais são importantes.

Há poucos dados sobre a atividade antileishmania dos constituintes de M. citrifolia na literatura. Um ensaio clínico sobre a atividade antileishmania de $M$. citrifolia mostrou boa atividade para duas antraquinonas isoladas de extrato do caule, morindicona e morinthona (Sattar, et al., 2012). Antraquinonas isoladas deste gênero apresentaram atividade contra o crescimento do Plasmodium falciparum e promastigotas de L. major in vitro (Sittie, et al., 1999).

Camundongos C57BL/6 infectados com Leishmania amazonensis foram tratados por 60 dias com $500 \mathrm{mg} / \mathrm{kg}$ do suco de $M$. citrofolia, sendo observadas as cargas parasitárias, citocinas e expressões da matriz proteica extracelular do local da lesão. Histopatologia do local da lesão, linfonodos e fígado foram avaliados para analisar os processos inflamatórios. Também, citocinas e parâmetros bioquímicos de toxicidade foram avaliados. O tratamento com o suco diminuiu o tamanho da lesão e a carga parasitária. No local da infecção houve diminuição dos infiltrados inflamatórios e das expressões de citocinas (IL-12, TNF- $\alpha$, TGF- $\beta$ e IL-10). Por outro lado, este tratamento elevou as expressões proteicas da matriz extracelular de colágeno IV, fibronectina, bem como colágeno I e II, fibronectina e laminina. Não foi observada toxicidade no final do tratamento (Tabela 5) (Almeida-Souza, et al. 2016a).

Outro estudo utilizando L. amazonensis demonstrou que a atividade do suco da fruta de M. citrifolia é concentração dependente, porém, parece que o tempo de exposição não interfere na resposta. Semelhante ao estudo realizado com Leishmania infantum, as $\mathrm{CI}_{50}$ para L. amazonensis foi superior a $200 \mu \mathrm{g} / \mathrm{mL}$. Ressalta-se que em macrófagos não infectados houve elevação da produção de $\mathrm{H}_{2} \mathrm{O}_{2}$ (Tabela 5) (Almeida-Souza, et al., 2018).

Tabela 5. Atividade antileishmania de M. citrifolia.

\begin{tabular}{|c|c|c|c|}
\hline Amostras & Modelo e forma & Resultados obtidos & Referência \\
\hline SF & $\begin{array}{l}\text { Camundongos C57BL infectados } L \text {. } \\
\text { amazonensis } \\
500 \mathrm{mg} / \mathrm{kg} / 60 \mathrm{dias}\end{array}$ & $\begin{array}{l}\text { Redução da lesão } \\
\text { superior a glucantine }\end{array}$ & Almeida-Souza et al., 2016 (a) \\
\hline SF & Amastigota de L. infantum & $\mathrm{CI}_{50} 260,5 \mu \mathrm{g} / \mathrm{mL}$ & Almeida-Souza et al., 2016 (b) \\
\hline SF & Amastigotas de L. infantum & $\mathrm{CI}_{50} 201,3 \mu \mathrm{g} / \mathrm{mL}$ & Almeida-Souza et al., 2016 (b) \\
\hline SF & Amastigota L. amazonensis & $\mathrm{CI}_{50} 240,1 \mu \mathrm{g} / \mathrm{mL}$ & Almeida-Souza et al., 2018 \\
\hline
\end{tabular}

Legenda: SF- suco dos frutos; $\mathrm{CI}_{50}$ : Concentração Inibitória de 50\% dos parasitas. Fonte: Autores (2021).

\subsubsection{Atividades antimicrobiana, hipotensiva, hipoglicemiante e demais}

Três estudos realizados avaliaram atividade antimicrobiana na irrigação de canais radiculares de $M$. citrifolia, sendo observados redução na contagem média da Unidade Formadora de Colônias (UFC) de bactérias aeróbias e anaeróbias (Podar, et al., 2015) e prevenção de infecção causada por E. faecalis (Divia, et al., 2018). Ainda foi avaliado a eficácia antimicrobiana do extrato de $M$. citrifolia misturado com hidrocolóide irreversível para moldes dentais, sendo que as salivas dos pacientes que utilizaram esta moldagem apresentaram redução da contaminação por microrganismos, sem alterar a qualidade do material no molde final (Tabela 6) (Ahmed, et al., 2015). 
Research, Society and Development, v. 10, n. 4, e30210414149, 2021

(CC BY 4.0) | ISSN 2525-3409 | DOI: http://dx.doi.org/10.33448/rsd-v10i4.14149

Tabela 6: Atividade antimicrobiana como irrigante odontológico de Morinda citrifolia.

\begin{tabular}{|c|c|c|}
\hline Amostras & Modelos & Resultados \\
\hline $\mathrm{EEF}^{1}$ & Dentes infectados com E. faecalis & $\begin{array}{l}\text { UFC de E. faecalis: } \mathrm{MC}-158.17 \pm 19.83, \mathrm{NaOCl} \\
0.67 \pm 0.78\end{array}$ \\
\hline $\mathrm{SF}^{2}$ & $\begin{array}{l}\text { Dentes com necrose pulpar e } \\
\text { periodontite apical }\end{array}$ & Ativo em bactérias aeróbicas e anaeróbicas \\
\hline $\mathrm{EMC}^{3}$ & $\begin{array}{l}\text { Candida e Estreptococos em moldes } \\
\text { dentais }\end{array}$ & $\begin{array}{l}\text { UFC de Candida: antes } 2.9 \times 10^{2} \text { e depois } 0.98 \times 10^{2} \text {; } \\
\text { UFC de Estreptococos: antes } 2.2 \times 106 \text { e depois } \\
0.05 \times 10^{6}\end{array}$ \\
\hline
\end{tabular}

Legenda: EEF - Extrato Etanólico dos Frutos; SF- Suco dos Frutos; EMC - Extrato de Morinda citrifolia; MC Morinda citrifolia; $\mathrm{NaOCl}$ - Hipoclorito de Sódio; UFC - Unidade Formadora de Colônia. 1- Divia, et al., 2018; 2- Podar, et al., 2015; 3- Ahmed, et al., 2015. Fonte: Autores (2021).

Ratos hipertensos induzidos por dexametasona foram submetidos ao tratamento com extratos obtidos das folhas e frutos de $M$. citrifolia. Nos resultados obtidos os efeitos isolados ou combinados dos extratos na redução da pressão arterial sistêmica foram significativamente relevantes, porém o extrato dos frutos se mostrou mais efetivo em relação ao extrato das folhas $(\mathrm{EFo}=13.32 \%, \mathrm{EFr}=10.90 \%, \mathrm{EFo}+\mathrm{EFr}=19.58 \%$; Tabela 7; Wigati, et al., 2016). A hipertensão pode desenvolver-se como resultado do aumento da ROS (Beg, et al., 2011). Frutas maduras e folhas são fontes de antioxidantes (Yang, Gadi \& Thomson, 2011) que são capazes de evitar danos celulares devido ao estresse oxidativo. Compostos fenólicos têm a capacidade de capturar radicais livres e inibir a peroxidação lipídica, para que possa evitar danos celulares com redução e mecanismo de doadores de elétrons (Lee, et al., 2003; Nugroho, Malik \& Pramono, 2013).

O objetivo deste estudo foi determinar o efeito do consumo agudo do suco de $M$. citrifolia e amora na pressão arterial, frequência cardíaca e glicemia. Todos os participantes tiveram a pressão arterial (PA), tanto sistólica quanto diastólica BP (SBP e DBP), bem como frequência cardíaca (RH) e glicemia (BG), verificada. O consumo do suco de $M$. citrifolia causou uma queda significativa na SBP $(5 \%)$ e na DBP (7,5\%), enquanto o consumo de suco de amora diminuiu apenas 3,6\%. A BG dos participantes que consumiram o suco de M. citrifolia diminuiu 7,3\%, e o consumo agudo contribuiu para uma diminuição significativa da SBP, DBP e RH, bem como uma leve redução da BG (Tabelas 7, 8) (Nowak, et al., 2019). 
Tabela 7. Atividade hipotensiva de Morinda citrifolia.

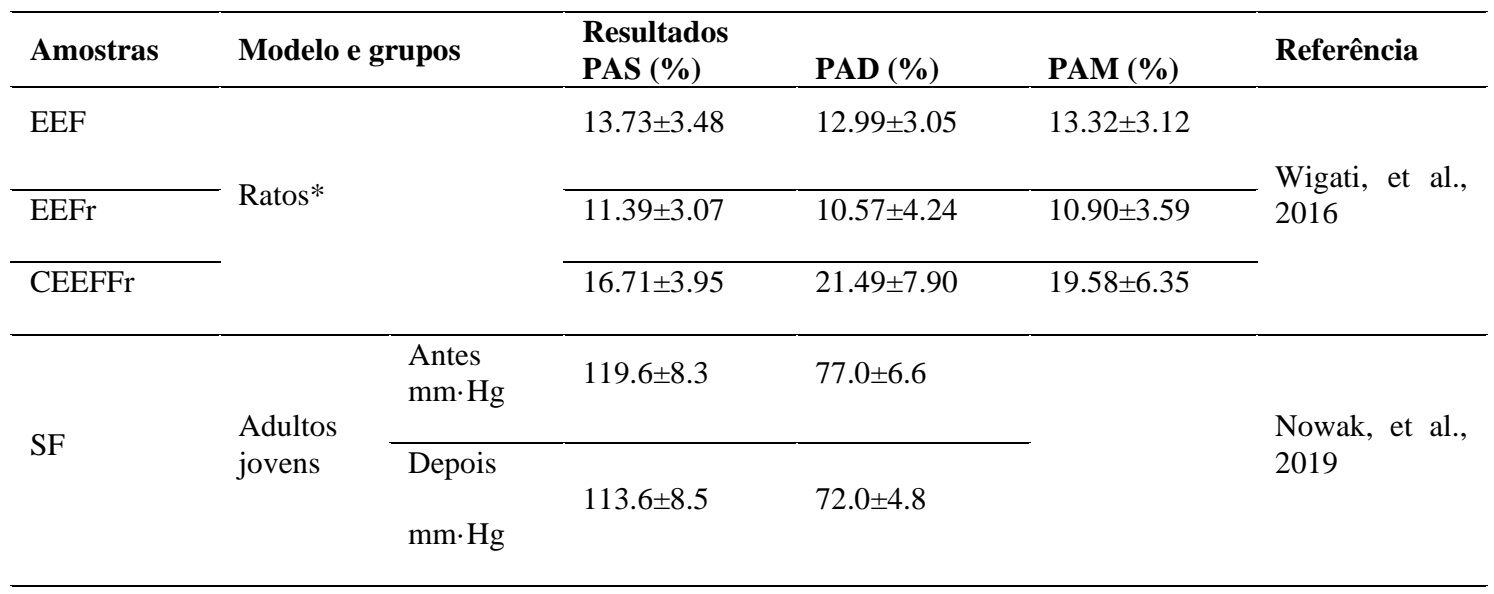

Legenda: SF: Suco dos Frutos; EEF: Extrato Etanólico obtidos das folhas; EEFr: Extrato Etanólico obtidos dos frutos; CEEFFr: Combinação do extrato etanólico obtidos das folhas e dos frutos; PAS: Pressão Arterial Sistólica; PAD: Pressão Arterial Diastólica; PAM: Pressão Arterial Média. *hipertensão induzida por dexametasona. Fonte: Autores (2021).

O efeito do consumo diário do suco da fruta de $M$. citrifolia sobre o estado fisiológico de pacientes com diabetes tipo 2 (DT2) foi avaliado durante um período de dois meses (8 semanas). O consumo do suco por 20 pacientes com DT2 resultou em uma diminuição média significativa do nível de açúcar no sangue matinal monitorado durante um período do estudo, não causando hipoglicemia em pacientes normoglicêmicos. Também reduziu o valor médio da hemoglobina glicada, nos valores de CRP, enquanto que nenhuma alteração foi observada em pacientes com valores normais. O nível de C-peptídeo mostrou um aumento médio significativo após quatro semanas de consumo de suco (Tabela 8) (Algenstaedt, Stumpenhagen \& Westendorf, 2018).

Visando investigar os possíveis mecanismos envolvidos na atividade hipoglicemiante, vários estudos vêm sendo desenvolvidos (Horsfall, et al., 2008; Nayak, et al., 2011; Lee, et al., 2012; Nerurkar, et al., 2012). Os resultados sugerem que o suco atue de modo similar à insulina, no entanto ocorre um efeito sinérgico para hipoglicemia quando utilizado de modo associado (Zang, et al., 2004), entretanto, outro estudo não demonstrou o efeito sinérgico desta associação (Lee, et al., 2012). A ativação da AMP-quinase (AMPK) via fosforilação leva a um aumento da absorção de glicose em adipócitos e células musculares (Horsfall, et al., 2008), quando usado o suco fermentado ocorre um aumento da fosforilação de AMPK (Lee, et al., 2012). Além disso, ocorre aumento da atividade do PPAR- $\gamma$, fator de transcrição que regula a expressão genética no fígado, tecido adiposo, endotélio vascular e músculo. A ativação do PPAR- $\gamma$ aumenta a expressão do transportador de glicose GLUT-4 e sua translocação na membrana celular dos adipócitos (Armoni, et al., 2003) e diminui a saída de glicose das células hepáticas (Nagashima, et al., 2005) melhorando homeostase de glicose.

Tabela 8. Atividade hipoglicêmica de Morinda citrifolia.

\begin{tabular}{lllll}
\hline & & Resultados* $\mathbf{( m g / d L )}$ & & \\
Amostras & Grupo & AT & DT & Referência \\
\hline SF & Saudáveis & 86,1 & 79,8 & Nowak, et al., 2019 \\
SF & Diabetes 2 & $139 \pm 23$ & $125 \pm 22$ & Algenstaedt, et al., 2018 \\
\hline
\end{tabular}

Legenda: SF: Suco dos Frutos; AT: Antes do tratamento; DT: Depois do tratamento; *Valores correspondentes a médias dos grupos. Fonte: Autores (2021).

Um estudo avaliou a eficácia na cicatrização de feridas do extrato das folhas de $M$. citrifolia no modelo de excisão de feridas, sendo observado aumento na contração da ferida em todos os grupos tratados com este extrato. Camundongos tratados 
com extrato tiveram um declínio na área da ferida em comparação com aqueles que receberam os tratamentos com gentamicina, no $3^{\circ}$ e $5^{\circ}$ dia de avaliação. Nos grupos tratados com extrato a contração foi superior ao controle, no $7^{\circ}, 9^{\circ}$ e $11^{\circ}$ dias de experimento. Quando tratados com uma solução contendo 1\% de extrato, a cicatrização atingiu 92,45\%, entretanto, quando se utilizou uma solução de $5 \%$ do extrato a resposta foi de $87,18 \%$, sendo superior ao controle $(54,46 \%)$, no $11^{\circ}$ dia de avaliação. A histologia da biópsia excisional da ferida cutânea no $11^{\circ}$ indicou que as estruturas da pele estavam dentro da epitelização normal em $1 \%(\mathrm{p} / \mathrm{v})$ de extrato, para 5\% (p / v) o tecido da pele também apresentou proliferação regenerativa semelhante à epiderme normal como a proliferação de baixo nível de fibroblastos, estrato córneo e camada de Malpighi. A triagem fitoquímica detectou a presença de flavonoides, triterpenóides, alcalóides, cumarinas, antraquinonas, saponinas, taninos, carotenóides, ácidos orgânicos e agentes redutores (Tabela 9) (Trieu Ly, et al., 2020).

Os flavonoides têm atividades antibacteriana, anti-inflamatória, antioxidante e cicatrização de feridas, redução da peroxidação lipídica, retardando o processo de necrose celular (Panche, Diwan \& Chandra, 2016). Entre os compostos presentes no extrato, a rutina é um flavonoide que possui atividade anti-inflamatória por meio de alguns sinais como ciclooxigenase-2 (COX-2), iNOS, p38 MAP quinase, JNK, inibe citocinas inflamatórias, tais como interleucina (IL) IL-4, IL5, IL-10, IL-13, IL-17, IL-31, IL-32 e interferon (INF) INF- $\gamma$. A rutina é formulada como hidrogel para diminuir o tamanho da ferida, reduzir a peroxidação lipídica, aumentar a atividade da catalase e promover a regeneração do tecido. Além disso, foi demonstrado que a rutina tem efeitos antioxidantes, anti-inflamatórios, antienvelhecimento e de proteção solar (Ganeshpurkar \& Saluja, 2017). Foi relatado que saponinas, triterpenóides e taninos têm atividade cicatrizante de feridas (Kim, et al., 2011; Barreto, et al., 2014; Su, et al., 2017). Portanto, o efeito cicatrizante pode ser atribuído à contribuição desses componentes químicos individuais (Trieu Ly, et al., 2020).

Outro estudo investigou os efeitos protetores do extrato das frutas de M. citrifolia (MCFE) na pancreatite aguda induzida por L-arginina em ratos, sendo que os grupos receberam $200 \mathrm{mg} / \mathrm{kg}$ e $400 \mathrm{mg} / \mathrm{kg}$ do MCFE, por 6 dias antes da administração da L-arginina. Após 12 h de indução, foi coletado o soro e analisados: amilase, lipase, proteína C-reativa, dismutase de superóxido, glutationa, catalase, nitrato tecidual, lactato desidrogenase e mieloperoxidase. Estudos histopatológicos e ensaio de fragmentação de ácido desoxirribonucleico (DNA) foram realizados a partir do tecido pancreático isolado. A administração do MCFE mostrou um efeito protetor significativo dependente de dose, melhorando os níveis de enzimas antioxidantes e reduzindo os níveis elevados de amilase e lipase. O dano celular acinar foi limitado em achados histopatológicos e um DNA intacto quando comparado ao controle da doença (Tabela 9) (Gadicherla, et al., 2019).

Fatores como a geração de radicais livres, juntamente com a liberação de mediadores inflamatórios contribuíram para os efeitos prejudiciais do pâncreas pela administração da L-arginina (Matalka, Mhaidat \& Fatlawi, 2013). A pancreatite induzida pela L-arginina está relacionada a um aumento no estresse oxidativo, aumentando os níveis de MDA, MPO e nitrito devido à peroxidação de lipídios de membrana e ativação de NOS (Mayer, McMahon \& Bowen, 1984). A administração do suco da $M$. citrifolia reduz os níveis radicais de ânion de superóxido de plasma em indivíduos fumantes, reduzindo os níveis de SOD no devido tempo reduzidos níveis de MDA (Ma, et al., 2013). Loganina, um iridoide presente na fruta, aumenta a atividade de glutationa em células de mesangial de ratos, o que pode contribuir para o aumento dos níveis de glutationa (Xu, et al., 2006). Além disso, a ativação induzível de óxido nítrico deriva óxido nítrico que é um mediador pró-inflamatório na geração de inflamação pancreática, e o MCFE tem efeitos inibitórios sobre óxido nítrico e prostaglandina $\mathrm{E}_{2}$, contribuindo para seus efeitos anti-inflamatórios (Dussossoy, et al., 2011).

Ainda foi avaliando o potencial dos extratos de folhas de $M$. citrifolia (MLE60) na prevenção do ganho de peso in vivo, sendo os ratos de Sprague-Dawley tratados com dieta rica em gordura (HFD), com ou sem suplementação MLE60 (150 e $350 \mathrm{mg} / \mathrm{kg}$ de peso corporal) e avaliados para qualquer redução no ganho de peso, determinado a leptina plasmática, insulina, adiponectina e grelina de todos os grupos foram determinadas. A suplementação de MLE60 não afetou a ingestão alimentar 
indicando que a supressão do apetite pode não ser o principal mecanismo antiobesidade envolvido. Esta resposta pode estar associada a inibição da atividade lipase pancreática e lipoproteína lipase. Também o uso do extrato reduziu a deposição de gordura visceral e os níveis de LDL. O efeito antiobesidade deve estar relacionado a catequina, kaempferol e rutina, que são três flavonoides (Tabela 9) (Jambocus, et al., 2017).

Rutina (MLE60 continha 16,46 $\pm 0,91 \mathrm{mg}$ de rutina/g de extrato de planta seca) é considerada mais potente na supressão da diferenciação celular 3T3-L1, de forma dependente de dose. Na fase de indução da adipogênese, a rutina suprimiu a atividade do desidrogenase de glicerol-3-fosfato e atividade de fatores adipogênicos como $\gamma$ receptor ativado por peroxissoma (PPAR- $\gamma$ ) e CCAAT/enhancer binding protein- $\alpha(\mathrm{C} / \mathrm{EBP} \alpha)$ em células 3T3-L1. In vivo, a suplementação de rutina ( 25 e $50 \mathrm{mg} / \mathrm{kg}$ de peso corporal) durante 4 semanas em camundongos C57BL/6 alimentados com HFD resultou em ganho de peso reduzido em comparação com os camundongos alimentados apenas com o HFD. O efeito antiobesidade da rutina foi mais provável de ser mediado pela regulação de certos fatores de transcrição adipogênica, como refletido pela regulação de PPAR- $\gamma$ e C/EBP $\alpha$ mRNA (Choi, et al., 2006). Em ratos Wistar obesos, uma intervenção de 8 semanas com 50 e $100 \mathrm{mg}$, o peso corporal e o tecido adiposo foi reduzido, com amenização nos perfis lipidoides soros, insulina, leptina, TG, nível de colesterol e perfis oxidativos, confirmando o efeito protetor da rutina na dislipidemia, na esteatose hepática e no estresse oxidativo (Hsu, et al., 2009).

O extrato obtido das folhas de $M$. citrifolia foi submetido a ensaios para avaliar sua atividade na função hepática de ratas na menopausa, submetidas a dieta rica em gorduras e o impacto no ganho de peso, sendo ainda avaliado marcadores de estresse oxidativo do fígado, esteatose microvesicular difusa e mitocôndrias defeituosas. O tratamento com extrato preveniu a esteatose hepática, aumentando a enzima antioxidante do fígado SOD e GPx, aumentando ALP, diminuindo a infiltração de lipídios no fígado, prevenindo danos mitocondriais e, em geral, mantendo a histologia hepática normal e ultraestrutura. Em conclusão, fornecemos evidências histológicas e ultraestruturais detalhadas mostrando os efeitos hepatoprotetores do extrato da folha de M. citrifolia através de seu mecanismo antioxidante (Tabela 9) (Chong, et al., 2019).

A hidrólise das moléculas de gordura produz ácido graxo livre (FFA) e produtos de peroxidação lipídica, como aldeídos, cetonas e álcoois. A oxidação de lipídios gera radicais livres (ROS) iniciando a peroxidação de lipídios. O produto final da peroxidação lipídica é MDA, que é altamente mutagênico e no fígado causa inflamação (Jaeschke, Wang \& Esani, 1996) e estresse oxidativo levando a esteatose (Letterson, et al., 1996). Doses baixas do extrato de M. citrifolia contribuiu para o aumento do MDA, entretanto doses elevadas promoveu sua redução e maior atividade de enzimas antioxidantes (Anitha \& Mohandass, 2006), porém não alterou CAT e GSH (Chong, et al., 2019).

Pesquisadores avaliaram o perfil hematológico e bioquímico de ratos com toxicidade induzida por metotrexato (MTX) para determinar até que ponto o tratamento com M. citrifolia (MC) pode amenizar os efeitos prejudiciais induzidos pelo MTX. Os ratos utilizados no estudo foram divididos em 4 grupos: grupo 1 (controle), grupo 2 (tratados com MTX), grupo 3 (tratados com MC) e o grupo 4 (tratados com MC e MTX). O pré-tratamento com M. citrifolia mostrou efeito benéfico ao restaurar os níveis de RBCs (série eritrocitária), WBCs (série leucocitária) e hemoglobina, sugerindo o efeito melhorador na prevenção da supressão da medula óssea induzida por MTX. Os parâmetros bioquímicos quando avaliados mostraram uma diminuição significativa da glicose sérica e do colesterol sérico. Em relação a quantificação de creatinina, bilirrubina, proteína, ureia e ácido úrico no sangue, voltaram a níveis próximos do normal em animais suplementados com M. citrifolia. Dessa forma, o pré-tratamento com extrato aquoso de $M$. citrifolia melhorou os parâmetros bioquímicos e hematológicos de ratos tratados com MTX (Mhatre, et al., 2016). 
Tabela 9. Outras atividades farmacológicas de M. citrifolia.

\begin{tabular}{|c|c|c|}
\hline Amostras & Modelo & Resultados \\
\hline $\mathrm{EFo}^{1}$ & $\begin{array}{l}\text { Cicatrizante } \\
\text { camundongo }\end{array}$ & $\begin{array}{l}\text { CI50 antioxidante e anti-inflamatória de } 133,99 \text { e } 70,21 \mu \mathrm{g} / \mathrm{mL} \text {, } \\
\text { respectivamente }\end{array}$ \\
\hline $\mathrm{EFr}^{2}$ & $\begin{array}{l}\text { Prevenção da pancreatite } \\
\text { aguda }\end{array}$ & Dose dependente, reduz os níveis elevados de amilase e lipase \\
\hline $\mathrm{EFo}^{3}$ & Antiobesidade & Redução do ganho \\
\hline $\mathrm{EFr}^{4}$ & Prevenção da toxicidade & $\begin{array}{l}\text { restaurou os níveis de parâmetros bioquímicos e de células } \\
\text { sanguíneas diminuídas por indução do metotrexato }\end{array}$ \\
\hline $\mathrm{EFo}^{5}$ & hepatoproteção & $\begin{array}{l}\text { Prevenção da esteatose hepática, elevação das enzimas antioxidante } \\
\text { SOD e GPx, ALP e redução da infiltração de lipídios do fígado, } \\
\text { prevenindo danos mitocondriais }\end{array}$ \\
\hline
\end{tabular}

Legenda: EFo- extrato de folhas: EFr- extrato das frutas; $\mathrm{CI}_{50}$ : Concentração Inibitória de 50\%; GPx: Glutationa Peroxidase; SOD: Superóxido dismutase; ALP: Fosfatase Alacalina. 1- Trieu Ly, et al., 2020; 2- Gadicherla, et al., 2019; 3-Jambocus, et al., 2017; 4- Mhatre, et al., 2016; Chong, et al., 2019. Fonte: Autores (2021).

\subsection{Análises dos potenciais farmacológicos de Morinda citrifolia}

Vários estudos confirmaram que o suco obtido da fruta, extratos e compostos presentes na espécie são promissores para diferentes atividades farmacológicas. Após a leitura dos artigos fica clara a relação da capacidade antioxidante da espécie e as diferentes atividades biológicas, como atividades anti-inflamatória, hipoglicemiante, etc. (Tabela 10).

O estresse oxidativo reflete o desequilíbrio entre a defesa biológica e o sistema agressivo, mediado pela produção excessiva de espécies reativas de oxigênio (ROS), sendo que os mecanismos antioxidantes de neutralizá-los falharam (Patlevič, et al., 2016). As ROS têm sido associadas a danos celulares e peroxidação lipídica (Ayala, et al., 2014), parece haver uma relação direta entre a inflamação e o estresse oxidativo. Processos inflamatórios podem estar envolvidos em diferentes condições patológicas, tais como: doenças cardiovasculares (García, et al., 2017), renais (Biswas \& Lopes de Faria, 2010), hepáticas (Ambade \& Mandrekar, 2012), câncer (Reuter, et al., 2010), entre outras patológicas.

Nos eventos inflamatórios ocorre produção elevada de EROs no tecido, que pode estimular a via de sinalização para a produção de mediadores inflamatórios, como citocinas e quimiocinas pró-inflamatórias, resultando na migração celular inflamatória (Hussain, et al., 2016). Desta forma, o uso de produtos vegetais que contenham metabólitos com capacidade antioxidante pode modular o estresse oxidativo e reduzir a liberação de mediadores da inflamação, atuando como agentes antiinflamatórios (Barboza, 2018).

Estudos químicos realizado com a espécie M. citrifolia levou ao isolamento de alguns flavonoides, como a rutina, quercetina, isoquercetina e kaempferol rutinosídeo (Dussossoy, et al., 2016). Os flavonóides são compostos polifenólicos que têm uma variedade de efeitos biológicos, tais como: ação antimicrobiana, antiviral, antiulcerogênico, citotóxico, antineoplásico, mutagênico, anti-inflamatório, antioxidante, anti-hepatotóxico, anti-hipertensivo, hipolipidêmico e antiplaquetário (Formica \& Regelson, 1995). Além disso, eles possuem uma hidroxila que pode atuar como doadora de prótons e eliminar os radicais (Nickavar, Kamalinejad \& Izadpanah ,2007; Wojdylo, Oszmianski \& Czemerys 2007).

Flavonoides inibem as enzimas responsáveis pela produção do ânion superóxido como a xantina oxidase (Hanasaki, Ogawa, \& Fukui, 1994) e a proteína quinase C (Ursini, et al., 1994), também outras envolvidas na geração de EROs, como: ciclooxigenase, lipoxigenase, monooxigenase microssomal, glutationa S-transferase, succinoxidase mitocondrial, e NADH oxidase (Korkina \& Afanas'ev, 1997; Brown, et al., 1998). Além disso, podem quelar metais como ferro e cobre que são potencializadores da formação de EROs, dentre estes pode-se citar a redução do peróxido de hidrogênio com geração do radical hidroxila (Pietta, 2000). Flavonoides são termodinamicamente capazes de reduzir os radicais livres altamente oxidantes (Buettner, 1993) como superóxido, peroxil, alcoxil e radicais hidroxil (Torel, Cillard \& Cillard, 1986; Hussain, Cillard \& 
Cillard, 1987; Robak \& Gryglewski, 1988) e o radical aroxila pode reagir com um segundo radical, adquirindo uma estrutura quinona estável. A última reação pode ocorrer na presença de altos níveis de íons metálicos transitórios e é responsável pelo efeito pró-oxidante indesejado dos flavonoides (McCord, 1995). Assim, a capacidade geral dos flavonoides de agir como antioxidantes não depende apenas do potencial redox, mas também sobre possíveis reações do radical aroxil. A eliminação do superóxido é importante, porque esse radical está nas células aeróbias e é um potencial precursor do radical hidroxila (Cao, Sofic, \& Prior, 1997). Ainda, os flavonoides podem estabilizar os radicais por complexação com eles (Shadidi, Janitha, \& Wanasundara, 1992). Em síntese, os flavonoides podem estar envolvidos em várias atividades biológicas da M. citrifolia.

Ainda da M. citrifolia foram isolados iridoides e parece que estes possuem potencial anti-inflamatório. Outro estudo demonstrou que iridoides inibem a ciclooxigense 1 e 2 (Suksamrarn, et al., 2002). Além disso, iridoides exibem uma ampla gama de atividades farmacológicas, como cardiovascular, hepatoproteção, hipoglicemia, antimutagênica, antiespasmódica, antitumoral, antiviral, imunomodulação e efeitos purgativos (Viljoen, Mncwangi \& Vermaak, 2012). Outro estudo demonstrou que através da atividade antioxidante de iridoide é possível relacionar essa atividade ao efeito anti-inflamatório (Vaijanathappa, \& Badami, 2009).

A atividade antitumoral de $M$. citrifolia foi relacionada às antraquinonas (Sukamporn, et al., 2016) e já existem disponíveis fármacos antitumorais com esta classe química. Os fármacos anticâncer das antraquinonas realizam suas atividades citotóxicas por meio de sua interação com o DNA e inibição da atividade da topoisomerase II (Al-Otaibi, Spittle, \& El Gogary, 2017). Além disso, outros alvos podem estar envolvidos na atividade desta classe, como: telomerase, quinases, metaloproteinases de matriz, DNA e diferentes fases de linhas celulares (Siddmurthi, et al., 2020). Além disso, antraquinonas podem atuar pela ativação de espécies reativas de oxigênio (ROS) -JNK, causando um aumento nos níveis de ROS, fosforilação de JNK e estresse mitocondrial. O citocromo c foi então liberado no citoplasma, que, por sua vez, ativou a via da protease da cisteína e, por fim, induziu a apoptose das células tumorais (Li, et al., 2020).

A via de sinalização induzida por ROS, JNK, ativa a apoptose, isto é, induz a expressão de proteínas pró-apoptóticas em células tumorais para ativar a apoptose através da via mitocondrial (Sui, et al. 2014; Schattauer, et al., 2019). JNK é um membro da família da proteína quinase ativada por mitogênio e é capaz de fosforilar e ativar c-Jun. JNK que está envolvido na regulação de processos biológicos, como proliferação celular, diferenciação celular, morte celular e respostas ao estresse, e ainda promove a expressão de p53, Bax, FasL e fator de necrose tumoral ao promover a atividade da proteína-1 ativadora do complexo de fator de transcrição ( $\mathrm{Li}$, et al., 2020). Em síntese, indiferente ao metabólito envolvido na atividade de $M$. citrifolia, parece que o estresse oxidativo sempre está envolvido na atividade farmacológica. 
Tabela 10. Análise do potencial farmacológico e possível(is) mecanismo(s) e metabólito(s) envolvido(s).

\begin{tabular}{|c|c|c|}
\hline Atividades & Análise de mecanismo e metabolito & Potencial \\
\hline Anti-inflamatório & Parece ter relação com a atividade antioxidante & Elevado \\
\hline Antitumoral & $\begin{array}{l}\text { Alterações de expressões gênicas e a apoptose pode ser responsável pela } \\
\text { atividade, sendo relacionada a antraquinona a atividade oxidante }\end{array}$ & Elevado \\
\hline Antileishmania & Múltiplas alterações no parasito & Baixo \\
\hline Antimicrobiana & Estudos limitados, porém, parece promissor com antimicrobiano & - \\
\hline Hipotensiva & $\begin{array}{l}\text { Reduziu a pressão de ratos hipertensos, esta atividade pode estar } \\
\text { relacionada ao potencial antioxidante. }\end{array}$ & Elevado \\
\hline Hipoglicemiante & $\begin{array}{l}\text { Aumento a atividade do PPAR- } \gamma \text {, fator de transcrição que regula a } \\
\text { expressão genética no fígado, tecido adiposo, endotélio vascular e músculo. } \\
\text { Ativação do PPAR- } \gamma \text { aumenta a expressão do transportador de glicose } \\
\text { GLUT-4 e sua translocação na membrana celular dos adipócitos }\end{array}$ & Elevado \\
\hline Cicatrizante & $\begin{array}{l}\text { Os flavonoides podem estar envolvidos no processo de cicatrização, } \\
\text { envolvendo a sua atividade antioxidante. }\end{array}$ & Elevado \\
\hline Pancreatite & Parece ter relação com a atividade antioxidante & Elevado \\
\hline Antiobesidade & $\begin{array}{l}\text { Rutina -supressão da diferenciação celular } 3 \mathrm{~T} 3-\mathrm{L} 1 \text {, na fase de indução da } \\
\text { adipogênese, a rutina suprimiu a atividade do desidrogenase de glicerol-3- } \\
\text { fosfato e de fatores adipogênicos como PPAR- } \gamma \text { e CCAAT/enhancer } \\
\text { binding protein- } \alpha(\mathrm{C} / \mathrm{EBP} \alpha) \text {, resultou em ganho de peso reduzido }\end{array}$ & Elevado \\
\hline $\begin{array}{l}\text { Prevenção } \\
\text { toxicidade }\end{array}$ & Parece que a atividade antioxidante está envolvida nesta atividade & Elevado \\
\hline Hepatoproteção & Parece que a atividade antioxidante está envolvida nesta atividade & Elevado \\
\hline
\end{tabular}

Legenda: PPAR- $\gamma$ : Receptor ativado por proliferadores de peroxissoma gama. Fonte: Autores (2021).

\section{Conclusão}

Os compostos fenólicos da $M$. citrifolia, como flavonoides, podem ser responsáveis pela atividade antioxidante, esta capacidade antioxidante pode estar envolvida na maioria das atividades farmacológicas da espécie. Outro metabólito envolvido na atividade anti-inflamatória é o iridoide, entretanto, seu mecanismo de ação pode ter similaridade aos flavonoides. Em relação às antraquinonas, o estresse oxidativo deve estar envolvido no mecanismo de apoptose.

Devido aos resultados disponíveis na literatura, torna-se urgente realizar estudos que visem identificar os compostos envolvidos nas atividades, bem como estabelecer sua toxicidade e confirmar se sua capacidade antioxidante é responsável pela atividade.

\section{Agradecimentos}

Os autores deste trabalho gostariam de agradecer ao Programa de Educação Tutorial da Faculdade de Farmácia da Universidade Federal do Pará pelo aparato financeiro para a realização deste estudo. Agradecemos ao CNPq, Edital Universal $2018(432458 / 2018-2)$.

\section{Referências}

Ahmed, A., Charles, P. D., Cholan, R., Rússia, M., Surya, R. \& Jailance, L. (2015). Antibacterial efficacy and effect of Morinda citrifolia L. mixed with irreversible hydrocolloid for dental impressions: A randomized controlled trial. Journal of Pharmacy and Bio Allied Sciences, 7(Supl 2), S597-S599. 10.4103/0975-7406.163562.

Algenstaedt, P., Stumpenhagen, A. \& Westendorf, J. (2018). The Effect of Morinda citrifolia L. Fruit Juice on the Blood Sugar Level and Other Serum Parameters in Patients with Diabetes Type 2. Evidence-Based Complementary and Alternative Medicine, 2018, 1-10. 10.1155/2018/3565427.

Almeida-Souza, F., Cardoso, F. O., Souza, B. V. C., Valle, T. Z. V., Sá, J. C., Oliveira, I. S. S., . . Calabrese, K. S. (2016a). Morinda citrifolia Linn. Reduces Parasite Load and Modulates Cytokines and Extracellular Matrix Proteins in C57BL/6 Mice Infected with Leishmania (Leishmania) amazonensis. PLoS Neglected Tropical Diseases, 10(8), e0004900. 10.1371/journal.pntd.0004900 
Almeida-Souza, F., Taniwaki, N. N., Amaral, A. C. F., Souza, C. S. F., Calebrese, K. S. \& Abreu-Silva, A. L. (2016b). Ultrastructural Changes and Death of Leishmania infantum Promastigotes Induced by Morinda citrifolia Linn. Fruit (Noni) Juice Treatment. Evidence - Based Complementary and Alternative Medicine, 2016, 1-9. 10.1155/2016/5063540.

Almeida-Souza, F., Oliveira, A. E. R., Silva, A. L. A. \& Calabrese, K. S. (2018). In vitro activity of Morinda citrifolia Linn. fruit juice against the axenic amastigote form of Leishmania amazonensis and its hydrogen peroxide induction capacity in BALB/c peritoneal macrophages. BMC Research Notes, 11(492), 1-7. 10.1016/j.actatropica.2019.01.021.

Al-Otaibi, J. S., Spittle, P. T., \& El Gogary, T. M. (2017). Interaction of anthraquinone anti-cancer drugs with DNA:Experimental and computational quantum chemical study. Journal of Molecular Structure, 1127, 751-60. 10.1016/j.molstruc.2016.08.007

Ambade, A., \& Mandrekar, P. (2012). Oxidative stress and inflammation: essential partners in alcoholic liver disease. International Journal of Hepatology, 2012(9), 1-9. 10.1155/2012/853175

Anitha T., \& Mohandass, S. (2006). Anti-oxidant activity of Morinda citrifolia on lymphoma-bearing mice. Ancient Science of Life, $26(1 \& 2), 85-88$.

Armoni M., Kritz N., Harel C., Bar-Yoseph, F., Chen, H., Quon, M. J. \& Karnieli, E. (2003). Peroxisome proliferador-activatou receptor- $\gamma$ reprime a atividade promotor glut4 em adipócitos primários, e rosiglitazone alivia esse efeito. Journal of Biological Chemistry, 278(33), 30614-30623. 10.1074/jbc. M304654200.

Ayala, A., Muñoz, M.F., \& Argüelles, S. (2014). Lipid Peroxidation: production, metabolism, and signaling mechanisms of malondialdehyde and 4-hydroxy2- nonenal. Oxidative Medicine and Cellular Longevity, 2014(360438), 1-31. 10.1155/2014/360438.

Barbosa, A. F., Costa, I. M., Zucolotto, S. M. \& Giordani, R. B. (2017). Morinda citrifolia: fatos e riscos sobre o uso do noni. Revista Fitos, 11(2), 119-249. doi 10.5935/2446-4775.20170027

Barboza, J. M. (2018). Potencial anti-inflamatório e perfil antioxidante do eugenol: uma revisão (Trabalho de Conclusão de Curso). Facudade de Farmácia, Universidade Federal da Paraíba. 36p.

Barreto, R., Albuquerque-Júnior, R., Araújo, A., Almeida, J. R. G. S., Santos, M. R. V., Barreto, A. S., \& Quintans-Júnior, L. J. (2014). A Systematic Review of the Wound-Healing Effects of Monoterpenes and Iridoid Derivatives. Molecules, 19(1), 846-862. 10.3390/molecules19010846.

Batista, J. A., Magalhães, D. A., Sousa, S. G., Ferreira, J. S., Pereira, C. M. C., Lima, J. V. N., \& Barbosa, A. L. R. (2019). Polysaccharides derived from Morinda citrifolia Linn reduce inflammatory markers during experimental colitis. Journal Ethnopharmacology, 248(112303). 10.1016/j.jep.2019.112303.

Beg M, Sharma V, Akhtar N, Gupta A, Mohd J. (2011). Role of antioxidants in hypertension. Journal, Indian Academy of Clinical Medicine, 12 (2), 122-127. https://www.researchgate.net/publication/286071790_Role_of_antioxidants_in_hypertension.

Biswas, S. K., \& Lopes de Faria, J. B. (2007). Which comes first: renal inflammation or oxidative stress in spontaneously hypertensive rats? Free Radical Research, 41(2), 216-224. 10.1080/10715760601059672.

Brandão, D. L. N., Martins, M. T., Silva, A. O., \& Almeida, A. D. (2020). Anti-malarial activity and toxicity of Aspidosperma nitidum Benth: a plant used in traditional medicine in the Brazilian Amazon. Research, Society and Development, 9(10), e5059108817. 10.33448/rsd-v9i10.8817.

Brasil. (2006). Política Nacional de Plantas Medicinais e Fitoterápicos (Série B. Textos Básicos de Saúde). Brasília: Ministério da Saúde.

Brasil. (2015). Programa Nacional de Plantas Medicinais e Fitoterápicos (1 ed., 2. Impres.). Brasília: Ministério da Saúde.

Brown, J. E., Khodr, H., Hider, R. C., \& Rice-Evans, C. (1998). Structural dependence of flavonoid interactions with Cu2+ ions: implications for their antioxidant properties. Biochem. J., 330, 1173-1178. 10.1042/bj3301173.

Buettner, G. R. (1993). The pecking order of free radicals and antioxidants: lipid peroxidation, alpha-tocopherol, and ascorbate. Arch. Biochem. Biophys., 300, 535-43. 10.1006/abbi.1993.1074.

Cao, G.; Sofic, E.; Prior, \& R. L. (1997). Antioxidant and prooxidant behavior of flavonoids: structure-activity relationships. Free Rad. Biol. Med., 22, 749760. 10.1016/s0891-5849(96)00351-6

Chen, J., Shi, X., Chen, Y., Liang, H., Cheng, C. \& He, Q. (2018). Neuroprotective effects of chloroform and aqueous fractions of noni juice against t-Butyl hydroperoxide-induced oxidative damage in SH-SY5Y cells. Food \& Nutrition, 62, 1-11. 10.29219/fnr.v62.1605.

Choi, I., Park, Y., Choi, H., \& Lee, E. H. (2006). Anti-adipogenic activity of rutin in 3T3-L1 cells and mice fed with high-fat diet. BioFactors, 26(4), 273-281. 10.1002/biof.5520260405.

Chong, C. L. G., Hussan, F., \& Othman, F. (2019). Hepatoprotective Effects of Morinda citrifolia Leaf Extract on Ovariectomized Rats Fed with Thermoxidized Palm Oil Diet: Evidence at Histological and Ultrastructural Level. Oxidative Medicine and Cellular Longevity, 2019, 1-10. $10.1155 / 2019 / 9714302$.

Degáspari, C. H., \& Waszczynskyj, N. (2004). Propriedades antioxidantes de compostos fenólicos. Visão Acadêmica, 5(1), 33-40.

Divia, A. R., Nair, M. G., Varughese, J. M., \& Kurien, S. A. (2018). Comparative evaluation of Morinda citrifolia, green tea polyphenols, and Triphala with $5 \%$ sodium hypochlorite as an endodontic irrigant against Enterococcus faecalis: An in vitro study. Dental Research Journal, 15(2), 117-122. https://pubmed.ncbi.nlm.nih.gov/29576775/.

Dussossoy, E., Brat, P., Bony, E., Boudard, F., Poucheret, P., Mertz, C., Giaimis, J., \& Michel, A. (2011). Characterization, anti-oxidative and antiinflammatory effects of Costa Rican noni juice (Morinda citrifolia L.). J. Etnopharmacol., 133(1), 108-15. 10.1016/j.jep.2010.08.063.

Dussossoy, E., Bichon, F., Bony, E., Portet, K., Brat, P., Vaillant, F., Michel, A. \& Poucheret, P. (2016). Pulmonary anti-inflammatory effects and spasmolytic properties of Costa Rican noni juice (Morinda citrifolia L.). J. Ethnopharmacol., 192, 264-272. 10.1016/j.jep.2016.07.038. 
Feuerer, M., Herrero, L., Cipolletta, D., Naaz, A., Wong, J., Nayer, A., \& Mathis, D. (2009) Lean, but not obese, fat is enriched for a unique population of regulatory T cells that affect metabolic parameters. Nat. Med., 15, 930-939. 10.1038/nm.2002.

Florentino, I. F., Silva, D. P.B., Silva, D. M., Cardoso, C. S., Moreira, A. L. E., Borges, C. L., . . Costa, E. A. (2017). Potential anti-inflammatory effect of LQFM-021 in carrageenan-induced inflammation: The role of nitric oxide. Nitric Oxide, 69, 35-44. 10.1016/j.niox.2017.04.006.

Formica, J. V., \& Regelson, W. (1995). Review of the biology of quercetin and related bioflavonoids. Food Chem. Toxicol., 33, $1061-80$.

Gadicherla, V., Challa, S. R., Rao, M. V. B., Kunda, P. K. \& Prudhvi, R. (2019). Morinda citrifolia (Noni) fruit protects the exocrine pancreatic dysfunction against L-arginine induced acute pancreatitis in rats. Pharmacognosy Magazine, 15(64), 328-364.

Ganeshpurkar, A., \& Saluja, A. K. (2017). The Pharmacological Potential of Rutin. Saudi Pharm. J., 25, 149-164. 10.1016/j.jsps.2016.04.025.

García, N., Zazueta, C., \& Aguilera-Aguirre, L. (2017). Oxidative Stress and Inflammation in Cardiovascular Disease. Oxidative Medicine and Cellular Longevity, 2017, 1-2. https://doi.org/10.1155/2017/5853238.

Gottlieb, M. G. V., Morassutti, A. L., \& Cruz, I. B. M. (2011). Transição epidemiológica, estresse oxidativo e doenças crônicas não transmissíveis sob uma perspectiva evolutiva. Scientia Medica, 21(2), 69-80.

Hanasaki, Y., Ogawa, S., \& Fukui, S. (1994). The correlation between active oxygens scavenging and antioxidative effects of flavonoids. Free Rad. Biol. Med., 16, 845-850. 10.1016/0891-5849(94)90202-x.

Horsfall A. U., Olabiyi O., Aiyegbusi A., Noronha C. C., \& Okanlawon, A. O. (2008). Morinda citrifolia fruit juice augments insulin action in SpragueDawley rats with experimentally induced diabetes. Nigeriano Quarterly Journal of Hospital Medicine, 18(3), 162-165. 10.4314/nqjhm.v18i3.45020.

Hsu, C. -L., Wu, C. -H., Huang, S. -L., \& Yen, G. -C. (2009). Phenolic compounds rutin and o-coumaric acid ameliorate obesity induced by high-fat diet in rats. J. Agr. Food Chem., 57, 425-431. 10.1021/jf802715t

Hussain, S. R., Cillard, J., \& Cillard, P. (1987). Hydroxyl radical scavenging activity of flavonoids. Phytochemistry, 26, 2489- 2491. 10.1016/S00319422(00)83860-1.

Hussain, T., Tan, B., Yin, Y., Blachier, F., Tossou, M. C, \& Rahu, N. (2016). Oxidative Stress and Inflammation: What Polyphenols Can Do for Us? Oxidative medicine and cellular longevity, 2016, 1-9. 10.1155/2016/7432797.

Ishibashi, Y., Matsui, T., Isami, F., Abe, Y., Sakaguchi, T., Higashimoto, Y., \& Yamagishi, S. I. (2017). N-butanol extracts of Morinda citrifolia suppress advanced glycation end products (AGE)-induced inflammatory actions in endothelial cells through its anti-oxidative properties. BMC Complementary and Alternative Medicine, 17(1), 1-6. 10.1186/s12906-017-1641-3.

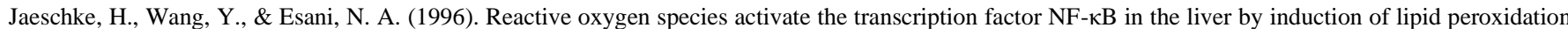
(abstract). Hepatology, 24, 238A.

Jambocus, N. G. S., Ismail, A., Khatib, A., Mahomoodally, F., Saari, N., Mumtaz, M. W., \& Hamid, A. A. (2017). Morinda citrifolia L. leaf extract prevent weight gain in Sprague-Dawley rats fed a high fat diet. Food Nutr. Res., 61(1), 1-13. 10.1080/16546628.2017.1338919.

Kamiya, K., Tanaka, Y., Endang, H., Umar, M., \& Satake, T. (2004). Chemical constituents of Morinda citrifolia fruits inhibit copperinduced low-density lipoprotein oxidation. J. Agric. Food Chem., 52(19), 5843-5848. 10.1021/jf040114k.

Kamiya, K., Tanaka, Y., Endang, H., Umar, M., \& Satake, T. (2005). New anthraquinone and iridoid from the fruits of Morinda citrifolia. Chem. Pharm. Bull., 53(12), 1597-1599. 10.1248/cpb.53.1597.

Kim, Y., Cho, I., Jeong, M., Jeong, S., Nah, S., Cho, Y. -S., Kim, S. -H., Go, A.-R., Kim, S.-E. \& Kang, -S.-S. (2011). Therapeutic Effect of Total Ginseng Saponin on Skin Wound Healing. J. Ginseng Res., 35, 360-367. 10.5142/jgr.2011.35.3.360.

Korkina, L. G., \& Afanas'ev, I. B. (1997). Antioxidant and chelating properties of flavonoids. Adv Pharmacol., 38, 151-63. 10.1016/s1054-3589(08)60983-7.

Lawson, C., \& Wolf, S. (2009). ICAM-1 signaling in endothelial cells. Pharmacol. Rep., 61, 22-32. 10.1016/S1734-1140(09)70004-0.

Lee, S. Y., Park, S. L., Hwang, J. T., Yi, S. H., Nam, Y. D., \& Lim, S. I. (2012). Antidiabetic Effect of Morinda citrifolia (Noni) Fermented by Cheonggukjang in KK-A(y) Diabetic Mice. Evidence-based Complementary and Alternative Medicine; 2012, 1-8. 10.1155/2012/163280.163280.

Lee, S. E., Hwang, H. J., Há, J. S., Jeong, H. S., \& Kim, J. H. (2003). Screening of medicinal plant extracts for antioxidant activity. Life Sci., 73, 167-179. $10.1016 / \mathrm{s} 0024-3205(03) 00259-5$

Letterson, P., Fromenty, B., \& Terris, B. (1996). Acute and chronic hepatic steatosis lead to in vivo lipid peroxidation in mice. Journal of Hepatology, 24(2), 200-208. 10.1016/s0168-8278(96)80030-4.

Li, Z., Wu, C., Ding, X., Li, W., Xue, L. (2020). Toll signaling promotes JNK-dependent apoptosis in Drosophila. Cell Div., 15,7. https://doi.org/10.1186/s13008-020-00062-5

Lim, S. -L., Mustapha, N. M., Goh, Y. -M, Bakar, N. A. A., \& Mohamed, S. (2016). Metastasized lung cancer suppression by Morinda citrifolia (Noni) leaf compared to Erlotinib via anti-inflammatory, endogenous antioxidant responses and apoptotic gene activation. Molecular and Cellular Biochemistry, 416, 8597. 10.1007 / s11010-016-2698-x.

Ma, D. L., Chen, M., Su, C. X., \& West, B. J. (2013). In vivo antioxidant activity of deacetylasperulosidic acid in noni. J. Anal Methods Chem., 2013 , 804504. https://doi.org/10.1155/2013/804504 
Matalka, I. I., Mhaidat, N. M., \& Fatlawi, L. A. (2013). Antioxidant activity of simvastatin prevents L-arginine-induced L-Arginine induced acute pancreatitis in rats. Int. J. Physiol Pathophysiol Pharmacol., 5(2), 102-108. https://www.ncbi.nlm.nih.gov/pmc/articles/PMC3669738/.

Matsui, T., Nakamura, N., Ojima, A., Nishino, Y., \& Yamagishi, S.I. (2016). Sulforaphane reduces advanced glycation end products (AGEs)-induced inflammation in endothelial cells and rat aorta. Nutr. Metab. Cardiovasc. Dis., 26(9), 797-807. 10.1016/j.numecd.2016.04.008.

Matsui, T., Nishino, Y., Takeuchi, M., \& Yamagishi, S. (2011). Vildagliptin blocks vascular injury in thoracic aorta of diabetic rats by suppressing advanced glycation end product-receptor axis. Pharmacol Res., 63(5), 383-388. 10.1016/j.phrs.2011.02.003.

Mayer, A.D., McMahon, M. J., Bowen, M., \& Cooper, E. H. (1984). C reactive protein: an aid to assessment and monitoring of acute pancreatitis. J. Clin. Pathol., 37(2), 207-211. 10.1136/jcp.37.2.207.

McCord, J. M. (1995). Superoxide radical: controversies, contradictions, and paradoxes. Proc. Exp. Biol. Med., 209(2), 112-117. 10.3181/00379727-20943885c.

Mhatre, B., \& Marar, T. (2016). Protective effect of Morinda citrifolia L. (fruit extract) on methotrexate-induced toxicities-hematological and biochemical studies. Cogent biology, 2(1), 1-7. https://doi.org/10.1080/23312025.2016.1207879

Nagashima K., Lopez C., Donovan D., Ngai, C., Fontanez, N., Bensadoun, A., \& Ginsberg, H. N. (2005). Effects of the PPARgamma agonist pioglitazone on lipoprotein metabolism in patients with type 2 diabetes mellitus. Journal of Clinical Investigation., 115(5), 1323-1332. 10.1172/JCI23219.

Narasimhan, K. K. S., Jayakumar, D., Velusamy, P., Srinivasan, A., Mohan, T., Ravi, D. B., \& Periandavan, K. (2019). Morinda citrifolia and Its Active Principle Scopoletin Mitigate Protein Aggregation and Neuronal Apoptosis through Augmenting the DJ-1/Nrf2/ARE Signaling Pathway. Oxidative Medicine and Cellular Longevity, 2019, 1-13. 10.1155/2019/2761041.

Nayak, B. S., Marshall, J. R., Isitor, G., \& Adogwa A. (2011). Hypoglycemic and Hepatoprotective Activity of Fermented Fruit Juice of Morinda citrifolia (Noni) in Diabetic Rats. Evidence-Based Complementary and Alternative Medicine, 2011, 1-5. 10.1155/2011/875293.

Nerurkar, P. V., Nishioka, A., Eck, P. O., Johns, L.M., Volper, E., \& Nerurkar V. R. (2012). Regulation of glucose metabolism via hepatic forkhead transcription factor 1 (FoxO1) by Morinda citrifolia (noni) in high-fat diet-induced obese mice. British Journal of Nutrition, 108(2), 218-228. $10.1017 /$ S0007114511005563.

Nickavar, B., Kamalinejad, M., \& Izadpanah, H. (2007). In vitro free radical scavenging activity of five Salvia species. Pak J. Pharm. Sci., 20(4), 291-294.

Nowak, D., Gos'Lin’Ski, M., Wesołowska, A., Berenda, K., \& Popławski, C. (2019). Effects of Acute Consumption of Noni and Chokeberry Juices vs. Energy Drinks on Blood Pressure, Heart Rate, and Blood Glucose in Young Adults. Evidence-Based Complementary and Alternative Medicine, 2019 (4), 1-9. $10.1155 / 2019 / 6076751$.

Nugroho, A.E., Malik, A., \& Pramono, S. (2013). Total phenolic and flavonoid contents, and in vitro antihypertension activity of purified extract of Indonesian cashew leaves (Anacardium occidentale L.). Int. Food Res. J., 20, 299-305.

Organização Mundial de Saúde (OMS). (1978). Atenção primária à saúde: relatório da Conferência Internacional sobre Atenção Primária à Saúde.

Panche, A. N., Diwan, A. D., \& Chandra, S. R. (2016). Flavonoids: An Overview. J. Nutr. Sci., 5, e47. 10.1017/jns.2016.41.

Patlevič, P., Vašková, J., Švorc, P., Vaško, L., \& Švorcd, P. (2016). Reactive oxygen species and antioxidant defense in human gastrointestinal diseases. Integrative medicine research, 5(4), 250-258. 10.1016/j.imr.2016.07.004.

Pereira, A. S., Shitsuka, D. M., Pereira, F. J., \& Shitsuka, R. (2018). Metodologia da pesquisa científica. Santa Maria: UFSM, NTE. https://repositorio.ufsm.br/bitstream/handle/1/15824/Lic_Computacao_Metodologia-Pesquisa-Cientifica.pdf.

Pietta, P.G. (2000). Flavonoids as antioxidants. Journal of Natural Products, 63, 1035-1042. 10.1021/np9904509.

Podar, R., Kulkarni, G. P., Dadu, S. S., Singh, S., \& Singh, S. H. (2015). In vivo antimicrobial efficacy of $6 \%$ Morinda citrifolia, Azadirachta indica, and 3\% sodium hypochlorite as root canal irrigants. European Journal of Dentistry, 9(4), 529-534. 10.4103/1305-7456.172615.

Potterat, O., \& Hamburger, M. (2007). Morinda citrifolia (Noni) fruit- phytochemistry, pharmacology, safety. Planta Médica, 73(3),1991-99. 10.1055/s-2007967115.

Rajivgandhi, G., Saravanan, K., Ramachandran G., Li, J.-L, Yin, L., Quero, F., \& Li, W. -J. (2020). Enhanced anti-cancer activity of chitosan loaded Morinda citrifolia essential oil against A549 human lung cancer cells. International Journal of Biological Macromolecules, 164, 4010-4021. 10.1016/j.ijbiomac.2020.08.169.

Rao, U. S. M., Subramanian, S. M. (2009). Biochemical evaluation of antihyperglycemic and antioxidative effects of Morinda citrifolia fruit extract studied in streptozotocin-induced diabetic rats. Medicinal Chemistry Research, 18(6), 433-446. 10.1007/s00044-008-9140-1.

Reuter, S., Gupta, S. C., Chaturvedi, M. M., \& Aggarwal, B. B. (2010). Oxidative stress, inflammation, and cancer: How are they linked? Free Radical Biology and Medicine, 49(11), 1603-1616. 10.1016/j.freeradbiomed.2010.09.006.

Robak, J., \& Gryglewski, R. J. (1988). Flavonoids are scavengers of superoxide anions. Biochem. Pharmacol., 37, 83-88. 10.1016/0006-2952(88)90169-4.

Sarmento, R. M. (2016). Efeitos citoprotetor e citotóxico de Annona glabra (Annonaceae). (Dissertação de Mestrado). Programa de Pós-Graduação em Ciências Farmacêuticas, Universidade Federal do Pará, Belém, PA, Brasil.

Sattar F. A., Ahmed F., Ahmed N., Sattar S. A., Malghani M. A. K., \& Choudhary M. I. (2012). A double-blind, randomized, clinical trial on the antileishmanial activity of a Morinda citrifolia (Noni) stem extract and its major constituents. Natural Product Communications, 7(2), 195-196. 
Schattauer, S. S., Bedini, A., Summers, F., Reilly-Treat, A., Andrews, M. M., Land, B. B., \& Chavkin, C. (2019). Reactive oxygen species (ROS) generation is stimulated by $\kappa$ opioid receptor activation through phosphorylated c-Jun N-terminal kinase and inhibited by p38 mitogen-activated protein kinase (MAPK) activation. J. Biol. Chem., 45, 16884-16896. 10.1074/jbc.RA119.009592.

Shadidi, F., Janitha, P. K., \& Wanasundara, P. D. (1992). Phenolic antioxidants. Crit. Rev. Food Sci., 32, 67-103. 10.1080/10408399209527581.

Shalan, N. A. A. M., Mustapha, N. M., \& Mohamed, S. (2016). Morinda citrifolia leaf enhanced performance by improving angiogenesis, mitochondrial biogenesis, antioxidant, anti-inflammatory \& stress responses. Food Chemistry, 212, 443-452. 10.1016/j.foodchem.2016.05.179.

Sharma, K., Pachauri, S. D., Khandelwal, K. Ahmad, H. Arya, A., Biala, P., Agrawal, S., Pandey, R.R., Srivastava, A., Srivastav, A., Saxena, J.K., Dwivedi, A. K. (2016). Anticancer Effects of Extracts from the Fruit of Morinda Citrifolia (Noni) in Breast Cancer Cell Lines. Drug Res, 66(3), 141-147. 10.1055/s0035-1555804.

Sittie A. A., Lemmich E., Olsen C. E., Hviid, L., Kharazmi, A., Nkrumash, F. K., \& Christensen, S. B. (1999). Structure-activity studies: in vitro antileishmanial and antimalarial activities of anthraquinones from Morinda lucida. Planta Medica, 65(3), 259-261. 10.1055/s-2006-960473.

Sousa, S. G., Oliveira, L. A., Magalhães D. A., Brito, T. V., Batista, J. A., Pereira, C. M. C., Costa, M.S., Mazulo-Neto, J.C.R., Filgueras, M.C., Vasconcelos, D.F.P., Silva, D.A., Barros, F.C.N., Sombra.V.G., Freitas, A.L.P., Paula, R.C.M., Feitosa, J.P.A., Barbosa, A. L. R. B. (2018). Chemical structure and antiinflammatory effect of polysaccharide extracted from Morinda citrifolia Linn (Noni). Carbohydrate Polymers, 197, 515-523. 10.1016/j.carbpol.2018.06.042.

Su, X., Liu, X., Wang, S., Li, B., Pan, T., Liu, D., Wang, F., Diao, Y., \& Li, K. (2017). Wound-healing promoting effect of total tannins from Entada Phaseoloides (L.) Merr. in rats. Burns. 2017, 43(4), 830-838. 10.1016/j.burns.2016.10.010.

Sui, X., Kong, N., Ye, L., Han, W., Zhou, J., Zhang, Q., He, C., \& Pan, H. (2014). p38 and JNK MAPK pathways control the balance of apoptosis and autophagy in response to chemotherapeutic agents. Cancer Lett., 344, 174-179. 10.1016/j.canlet.2013.11.019.

Sukamporn, P., Rojanapanthu, P., Silva, G., Zhang, X., Gritsanapan, W., \& Baek, S. J. (2016). Damnacanthal and its nanoformulation exhibit anti-cancer activity via cyclin D1 down-regulation. Life Sciences, 152, 60-66. 10.1016/j.1fs.2016.03.038.

Suksamrarn, A., Kumpun, S., Kirtikara, K., Yingyongnarongkul, B., \& Suksamrarn, S. (2002). Iridoids with Anti-Inflammatory Activity from Vitex peduncularis. Planta Medica, 68(1), 72-73. 10.1055/s-2002-20048.

Takenaka, K., Yamagishi, S., Matsui, T., Nakamura, K., \& Imaizumi, T. (2006). Role of advanced glycation end products (AGEs) in thrombogenic abnormalities in diabetes. Curr. Neurovasc. Res., 3(1), 73-77. 10.2174/156720206775541804.

Torel, J., Cillard, J., \& Cillard, P. (1986). Antioxidant activity of flavonoids and reactivity with peroxy radical. Phytochemistry, 25, 383-5. 10.1016/S00319422(00)85485-0.

Trieu Ly, H., Nguyen, M. T. P., Nguyen, T. K. O., Bui, T. P. Q., Ke, X., \& Le, V. M. (2020). Phytochemical analysis and wound-healing activity of noni (Morinda citrifolia) leaf extract. Journal of Herbs, Spices \& Medicinal Plants, 26(4), 379-393. 10.1080/10496475.2020.1748159.

Ursini, F., Maiorino, M., Morazzoni, P., Roveri, A., \& Pifferi, G. (1994). A novel antioxidant flavonoid (IdB 1031) affecting molecular mechanisms of cellular activation. Free Rad. Biol. Med., 16, 547-53. 10.1016/0891-5849(94)90054-X.

Vaijanathappa, J., \& Badami, S. (2009) Antiedematogenic and free radical scavenging activity of swertiamarin isolated from Enicostema axillare. Planta Med., 75, 12-17. 10.1055/s-0028-1088333.

Vásquez, S. P. F., Mendonça, M. S., \& Noda, S. N. (2014). Etnobotânica de plantas medicinais em comunidades ribeirinhas do Município de Manacapuru, Amazonas, Brasil. Acta Amazonica, 44(4), 457 - 472. https://doi.org/10.1590/1809-4392201400423.

Viljoen, A., Mncwangi, N., \& Vermaak, I. (2012). Anti-inflammatory iridoids of botanical origin. Curr. Med Chem., 19(14), 2104-27. $10.2174 / 092986712800229005$.

Wang, M. Y. \& Su, C. (2001). Cancer preventive effect of Morinda citrifolia (Noni). Annals of the New York Academy of Sciences, 952(1), 161-168. 10.1111/j.1749-6632.2001.tb02737.x.

Wang, M., Wang, Q., Yang, Q., Yan, X., Feng, S. \& Wang, Z. (2020). Comparison of anthraquinones, iridoid glycosides and triterpenoids in Morinda officinalis and Morinda citrifolia using UPLC/Q-TOF-MS and multivariate statistical analysis. Molecules, 25(1), 1-16. 10.3390/molecules25010160.

Wang, X., Shi, L., Wang, X., Feng, Y. \& Wang, Y. (2019). MDG-1, an ophiopogon polysaccharide, restrains process of non-alcoholic fatty liver disease via modulating the gut-liver axis, Int. J. Biol. Macromol., 141, 1013-1021. 10.1016/j.ijbiomac.2019.09.007.

West, B. J., Tani, H., Palu, A. K., Tolson, C. B., \& Jensen, C. J. (2007). Safety tests and antinutrient analysis of noni (Morinda citrifolia L.) leaf. Journal of the Science of Food and Agriculture, 87(14), 2583-88. https://doi.org/10.1002/jsfa.3007.

Wigati, D., Anwar, K., Sudarsono, \& Nugroho, A. E. (2016). Hypotensive activity of ethanolic extracts of Morinda citrifolia L. leaves and fruit in dexamethasone-induced hypertensive rat. Evidence-Based Complementary and Alternative Medicine, 22(1), 107-113. 10.1177/2156587216653660.

Wigati, D., Anwar, K., Sudarsono, Nugroho, A.E. (2017). Hypotensive activity of ethanolic extracts of Morinda citrifolia L. leaves and fruit in dexamethasone-induced hypertensive rat. J. Evid. Based Complement. Altern. Med., 22, 107-113

Wojdylo, A., Oszmianski, J., \& Czemerys, R. (2007). Antioxidant activity and phenolic compounds in 32 selected herbs. Food Chemistry, 105(3), 940-949.

Xu, H., Shen, J., Liu, H., Shi, Y., Li, L., \& Wei, M. (2006). Morroniside and loganin extracted from Cornus officinalis have protective effects on rat mesangial cell proliferation exposed to advanced glycation end products by preventing oxidative stress. Can. J. Physiol Pharmacol., 84(12), 1267-73. 10.1139/y06-075. 
Research, Society and Development, v. 10, n. 4, e30210414149, 2021

(CC BY 4.0) | ISSN 2525-3409 | DOI: http://dx.doi.org/10.33448/rsd-v10i4.14149

Yang, J., Gadi, R., \& Thomson T. (2011). Antioxidant capacity, total phenols, and ascorbic acid content of noni (Morinda citrifolia) fruits and leaves at various stages of maturity. Micronesica., 41,167-176.

Yang, X., Lin, C., Cai, S., Li, W., Tang, J., \& Wu, X. (2019). Therapeutic effects of noni fruit water extract and polysaccharide on oxidate sstres and inflammation in mice under higt-fat diet. Food \& Function, 11(1), 1133-1145. 10.1039/c9fo01859j.

Yang, X., Mo, W., Zheng, C., Li, W. Tang, J., \& Wu, X. (2020). Alleviating effects of noni fruit polysaccharide on hepatic oxidative stress and inflammation in rats under a high-fat diet and its possible mechanisms. Food \& Function, 11(4), 2953-2968. 10.1039/d0fo00178c.

Yokozawa, T., Kang, K.S., Park, C.H., Noh, J.S., Yamabe, N., Shibahara, N., \& Tanaka T. (2010). Bioactive constituents of Corni Fructus: the therapeutic use of morroniside, loganin, and 7-O-galloyl-D-sedoheptulose as renoprotective agents in type 2 diabetes. Drug Discov Ther., 4(4), $223-34$.

Zang, M., Zuccollo, A., Hou, x., Negata, D., Walsh, K., Herscovitz, H., Brecher, P., Ruderman, N. B., \& Cohen, R. A. (2004). AMP-activated protein kinase is required for the lipid-lowering effect of metformin in insulin-resistant human HepG2 cells. Journal Of Biological Chemistry, 279(46), 47898-905. 10.1074/jbc.M408149200. 